المرأة الجزائربة و القوانـين العرفية للمجتمعر القبائلي خلال القرز 19

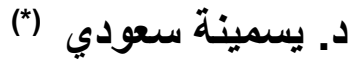

ملفمر:

تعد المرأة اللبنة الأساسية لأي مجتمع، فهي العمود الفقري لها، إذ إذات

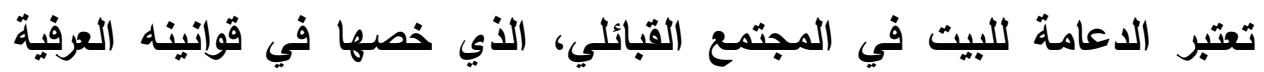

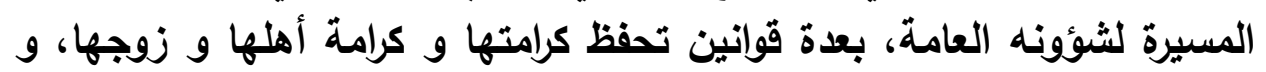

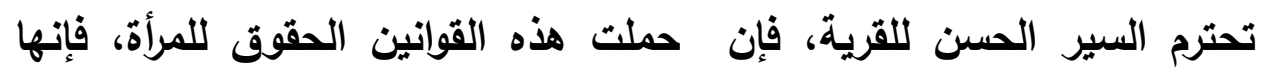
نهتها من الخروج عن طاعة زوجها و قريتها، فإن لم تحترم ذلك فهي معرضة فئن

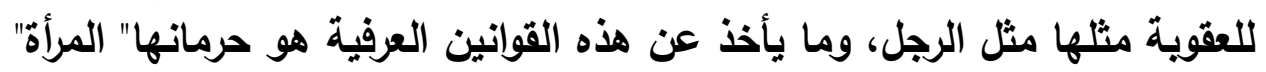

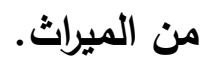

\title{
الكلمات المفنتامية:
}

المرأة، المجتمع القبائلي، المجتمع المشدالي، القوانين العرفية، الحرمان ، الميراث، الظروف الإجتماعية.

******

لما كانت القبيلة والجماعة، القوة الرادعة لكل محاولة خارجية لإسقاطها، لما تتميز به مجتمعاتها من تماسك، ونشاط حيوي، فكرت الإدارة الفرنسية بالقضاء

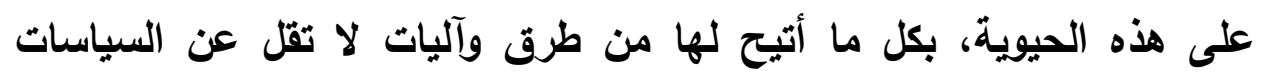

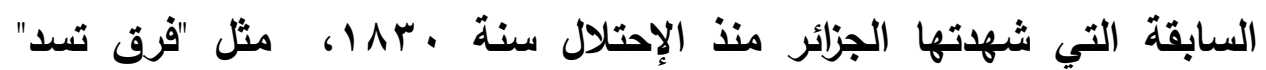

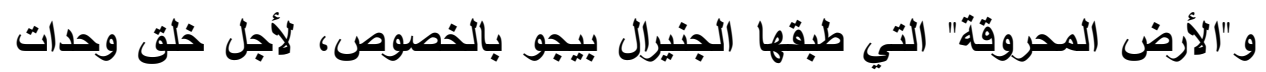

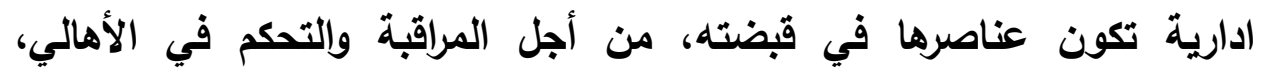

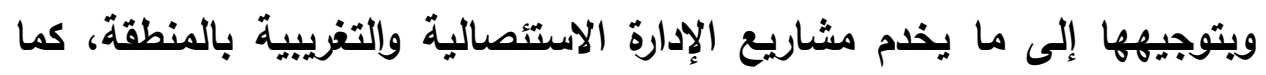

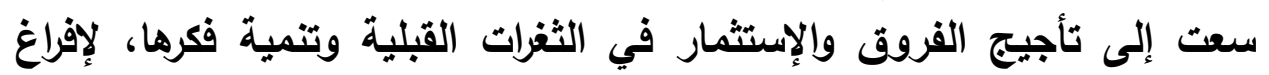
معنى "القبيلة" ومحتواها المتمثل في التكتل والتكافل الإجتماعي الذي كانئمان الني أهم دعائمه المرأة.

(")قتسم التاريخ، كلية العلوم الإنسانية، جامعة الجزائر ب أبو القاسم سعد الله 
فربطت علاقة النسب بين القرى، والأثخاص فهو الأسلوب الأي إستعمله مثلا، المرابطون لإستمالة أهل مشدالة، وينية الظقر بالإحترام والمكانة بين سكانها، قامت بجلب طلبة المدارس القرآنية المسماة بـ "ثمعمرين" مفردة

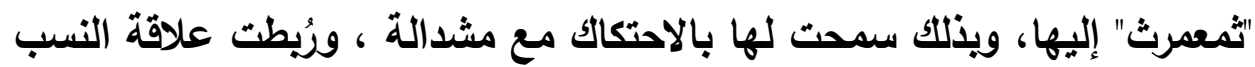
من هذه العائلات الشريفة، التي بلأت تتزوج بغير المرابطات القبائليات، ولكن العكس غير وارد، فلا يمكن لمرابطة أن تقترن بقبائلي لا ينتمى إلى المرابطين، فالأستاذ سعيد شيبان يقول في سبب ذلك: رأن المرابطات متحببات، فالقبائلي

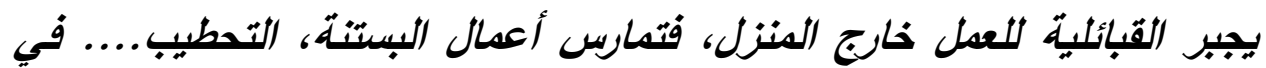

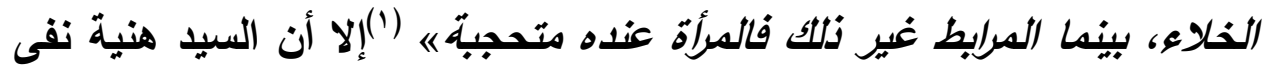

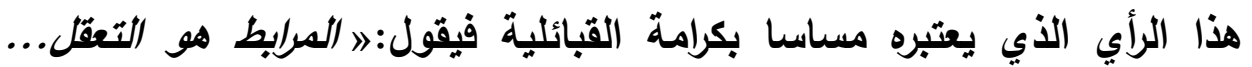

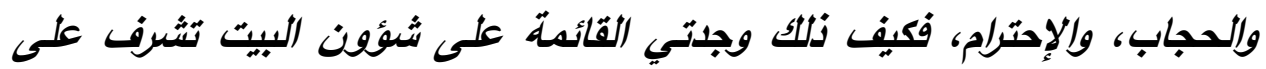

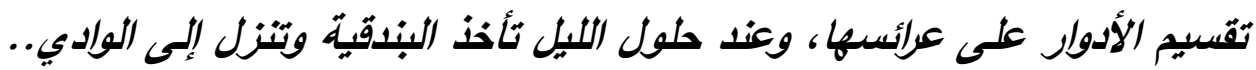

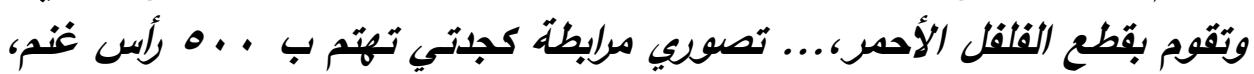

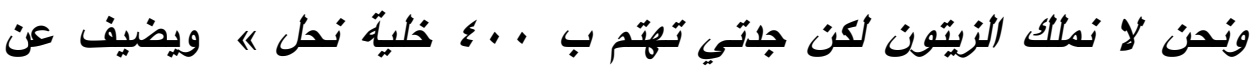

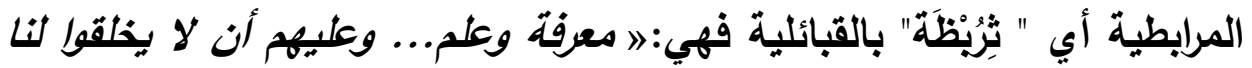

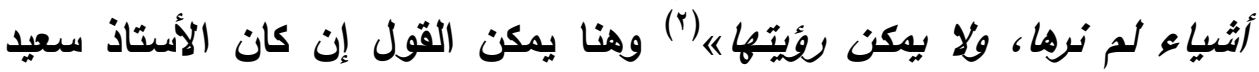

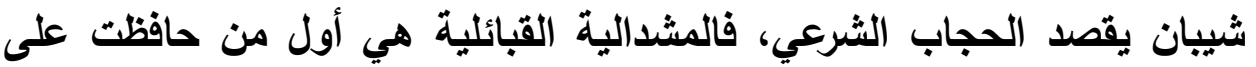

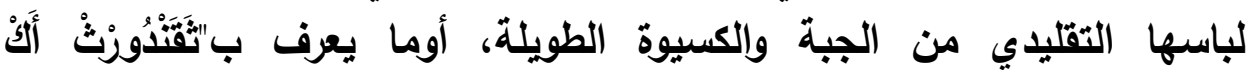

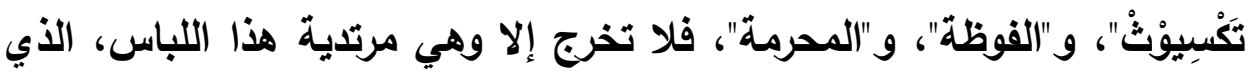

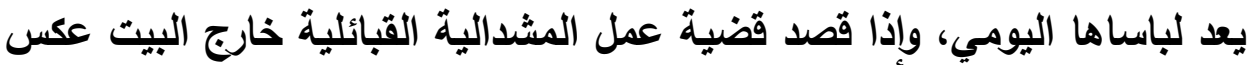
المرابطية، فكيف نفسر قول هنية الأي ينتمي لأهم العائلات المرابطية بوادي والية فيله

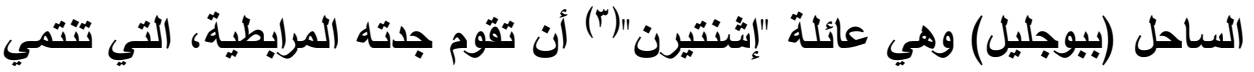

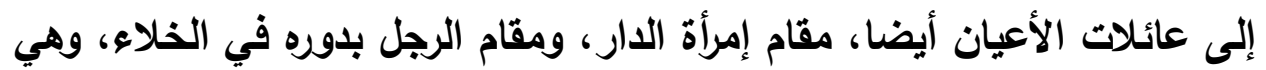

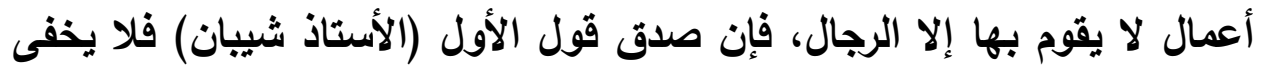
هذا عن أي واحد منا، فكيف لا ؟ والقبائلي صودرت كل أراضيه بفعل الاحتلال، الأل وظروف الحياة صعبة تحت ويلات الإستيطان، حتمت على القبائلية أن تساعد والهات

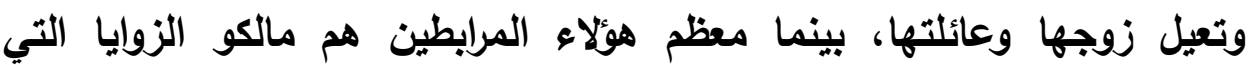

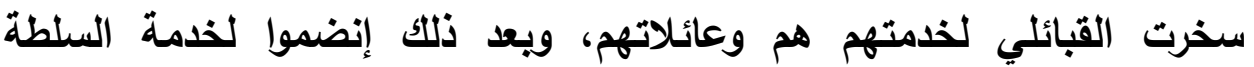


الفرنسية، التي منحت لهم كل وسائل الراحة من أموال وأراض... فلهذا فلا حاجة للمرابطة الخروج إلى الخلاء للعمل.

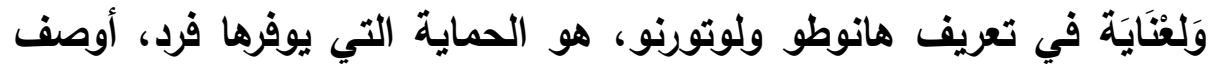

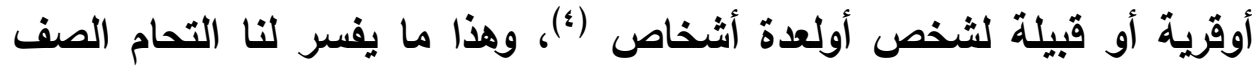

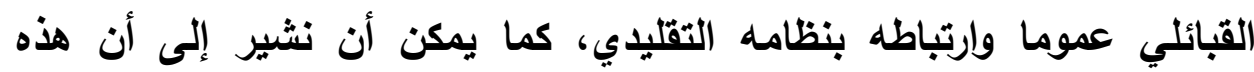

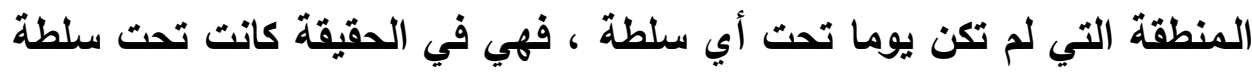

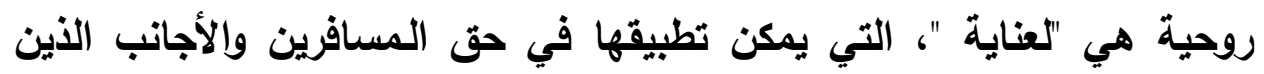

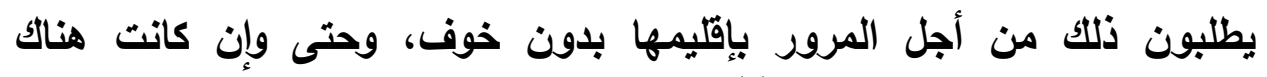
خصومات ومنازعات بين القبائل (ه).

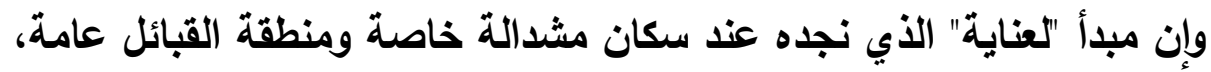

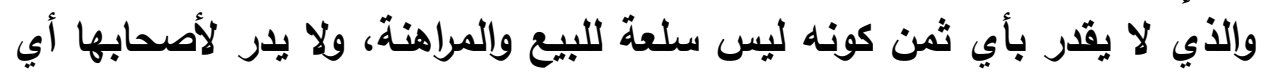

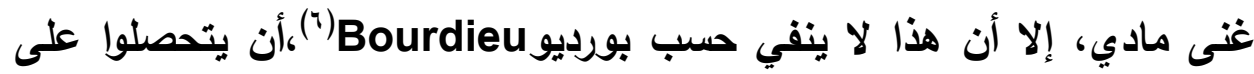

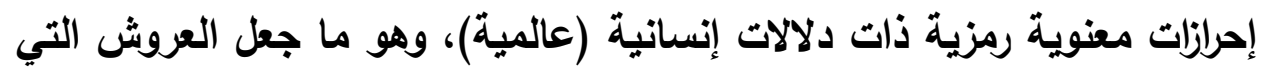

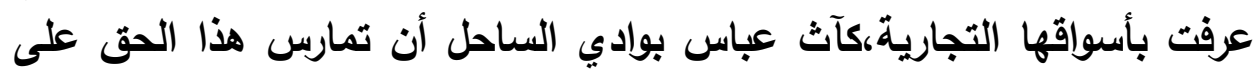

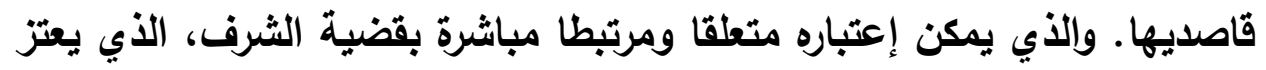
بها كل عرش من عروش منطقة القبائل.

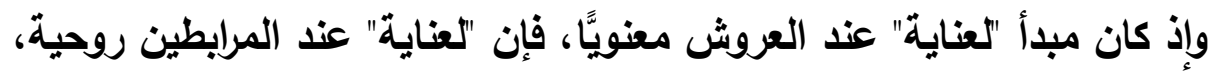

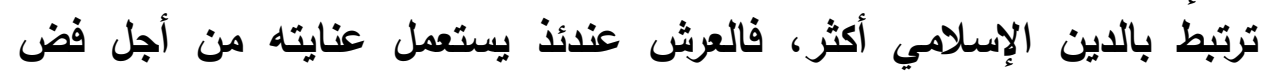

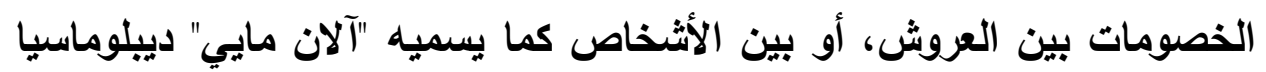

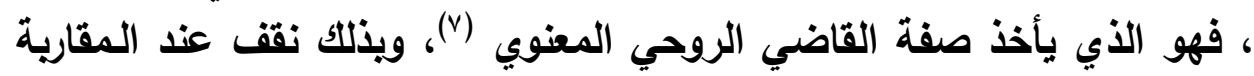

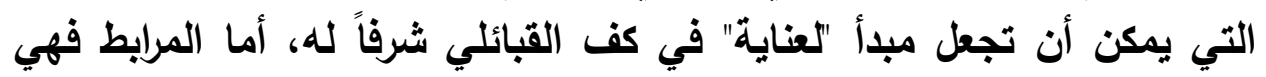
"بركة" له.

كما نشير إلى مكانة المرأة في مبدأ "لعناية"، الذي تمارسه في حق من يطلبها،

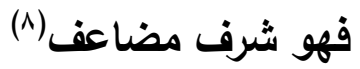

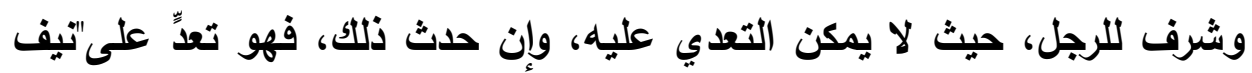

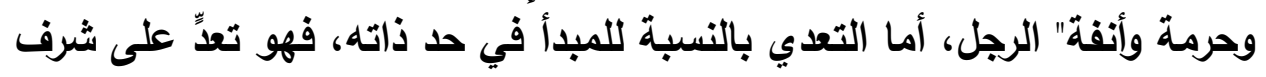

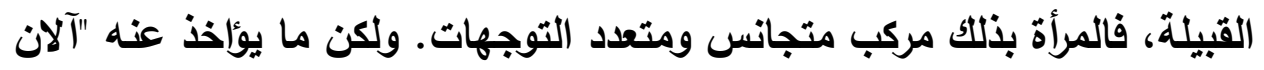
مايي" في تناوله لهذه النقطة، استعماله لكلمة "اللائيكي"بالنسبة للقبائليين 
عموما، ليميزهم عن المرابطين الذين إعتبرهم قضاة لخصومات اللائكيين،(وهم

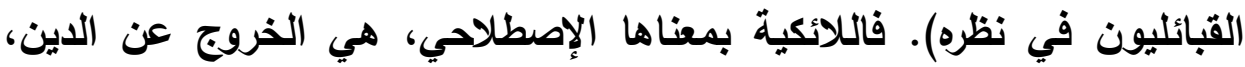

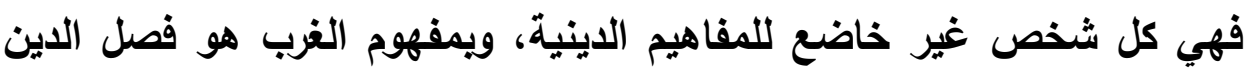

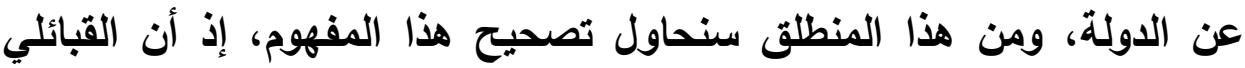

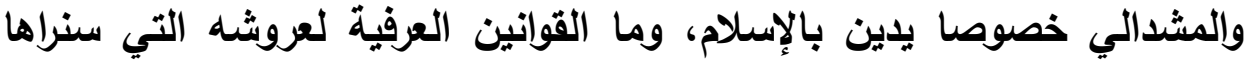

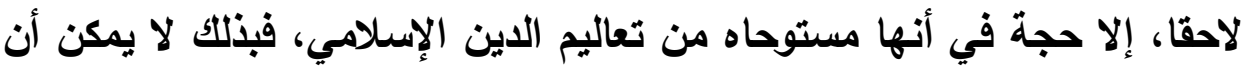

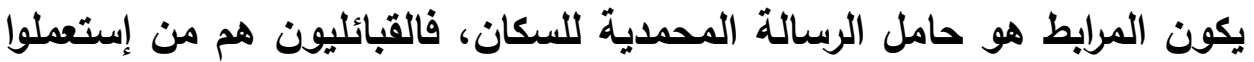

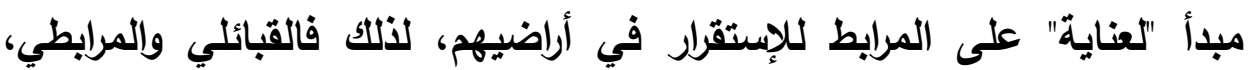

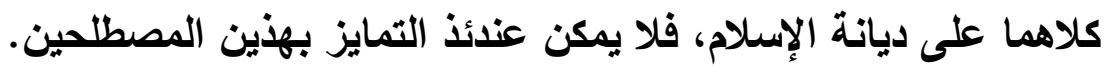

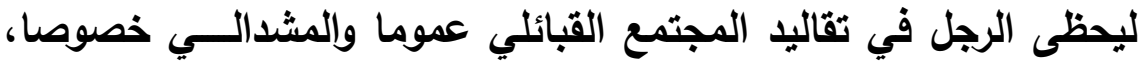

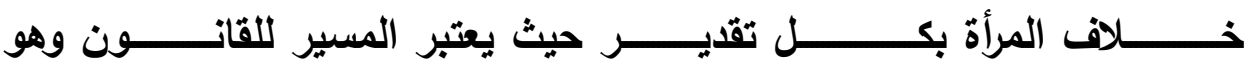
الـــــي يضعــه حسب رغبته(9)، ويذلك فهو الآمر والناهي للمرأة ليجعلها

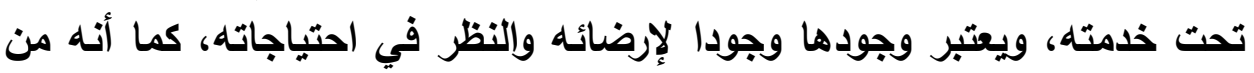

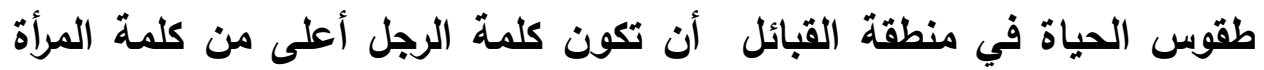

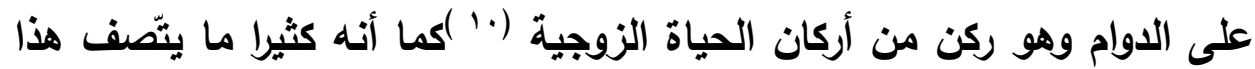

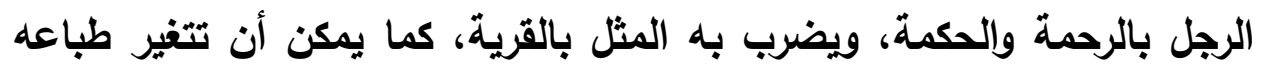

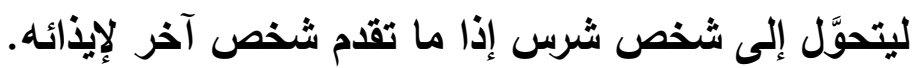

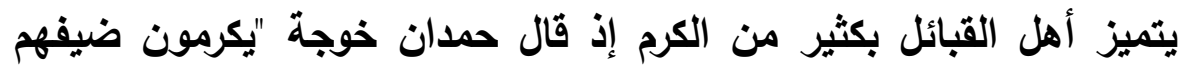

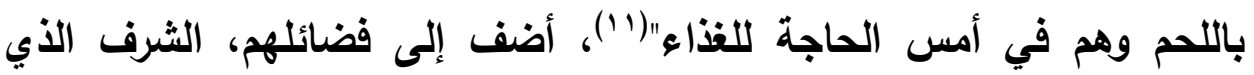

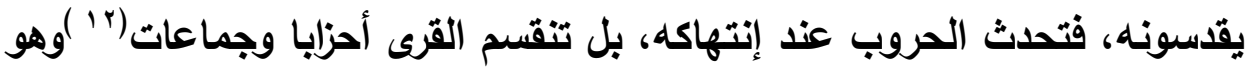

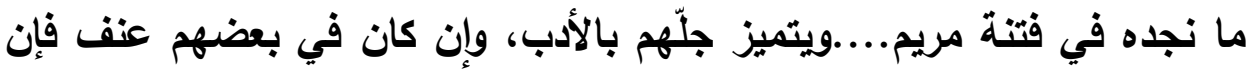

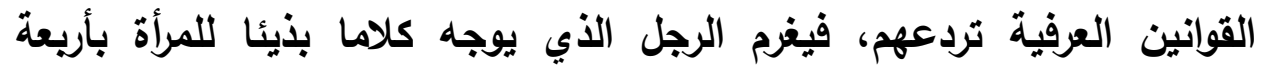

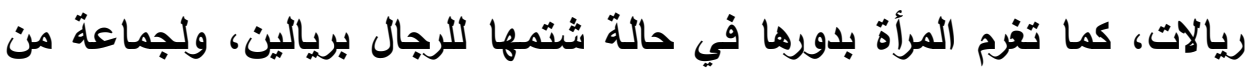

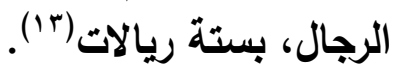
إضافة إلى أنَه يتربي على الفضائل ومكارم الأخلاق، ويكتسب خُلق التضامن

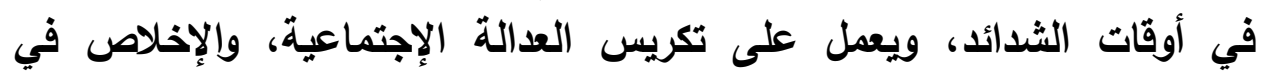

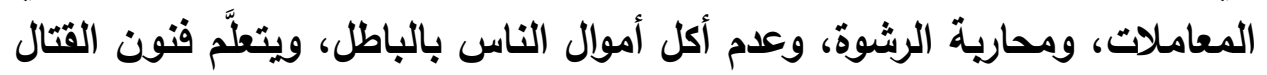

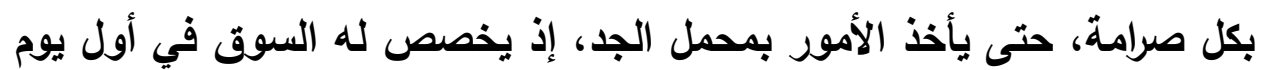


خروجه من البيت، لشراء رأس ثور، حتى يكون الرأس المدبر للقرية مستقبلا،

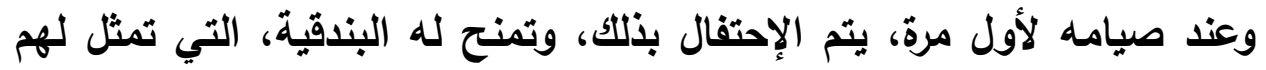

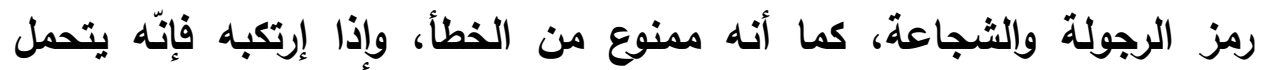

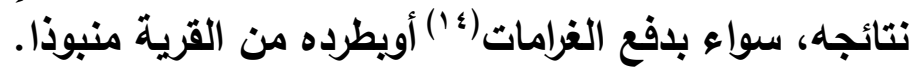

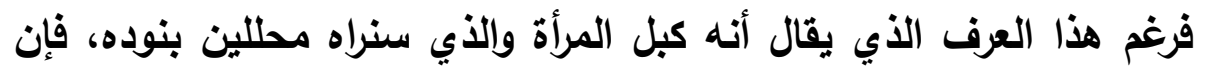

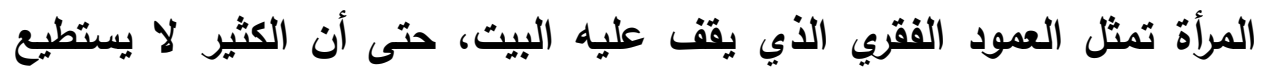

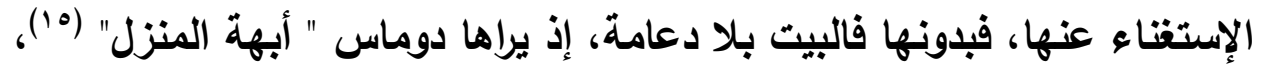

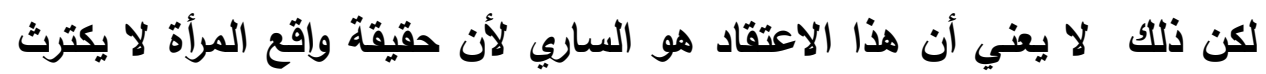

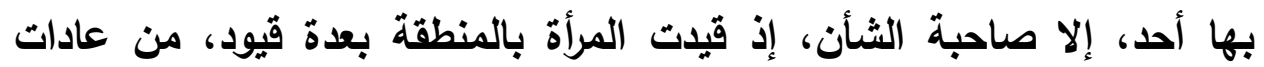

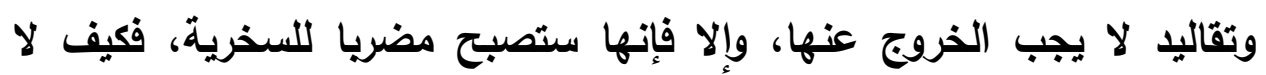

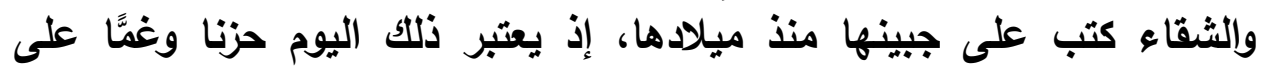

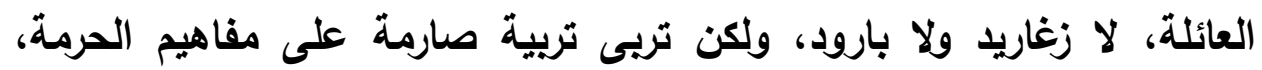

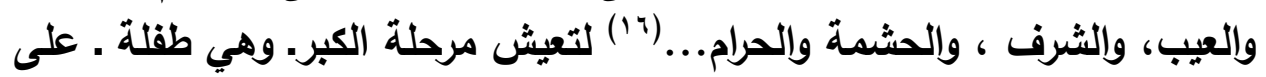

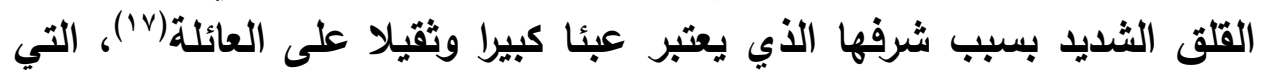

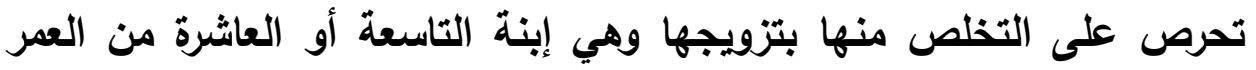

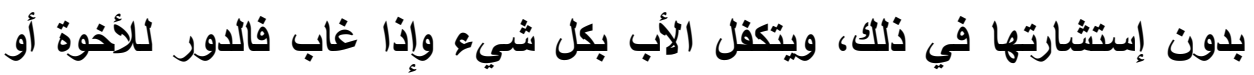

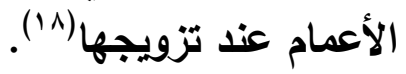

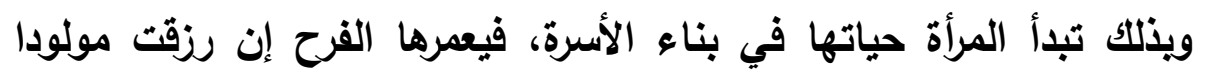

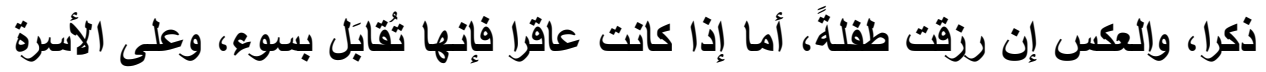

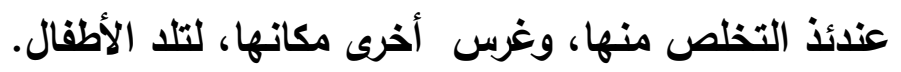

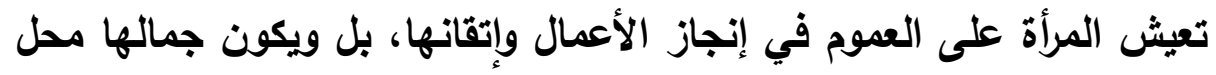

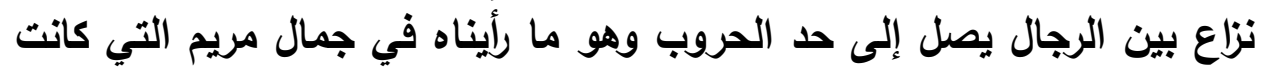
محل نزاع بين عروش مشدالة. أما فيما يخص مصيرها عند الطلاق، فهو متوقف على قرار الزوج، إن أراد

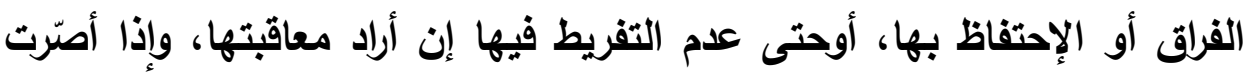

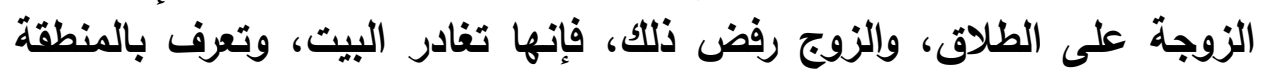

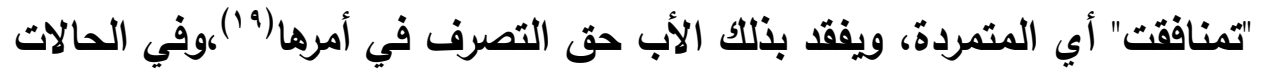

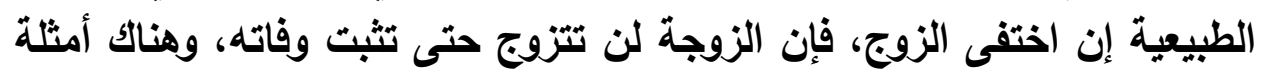


كثيرة عن ذلك، مثال المرأة التي انتظرت زوجها المنفي إلى" كايان" (·r)وحكم عليه بعشرين سنة، وقد إنتظرت الزوجة زوجها مدة، إلى أن غابت أخباره عن أن أنسان

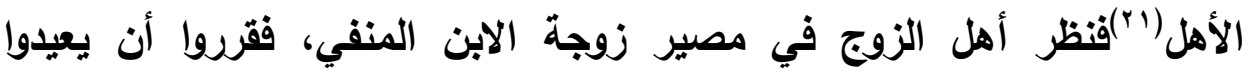

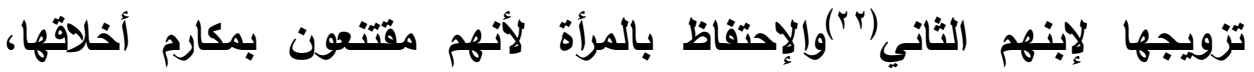
وقدرتها في إتقان أعمالها في البيت وخارجه، بالإضافة لهذا فإن المرأة بالمنطقة غالبا لا تأخذ حقها من الميراث.

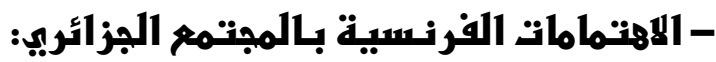

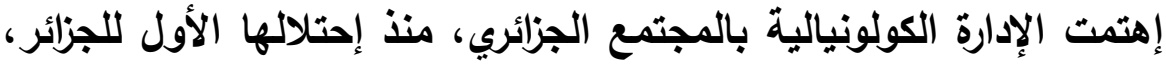

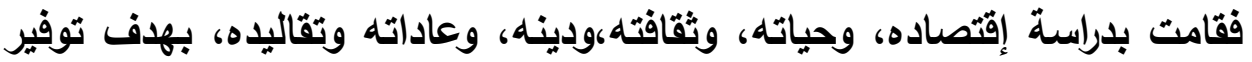
آليات لتجاح مشروعها الإستيطاني، وقت زاد الإهتمام بمنطقة القبائل للخصوصيات التي تميزت بها إجتماعيا، وثثافيا ولغويا، مما دفع بالقادة الإن

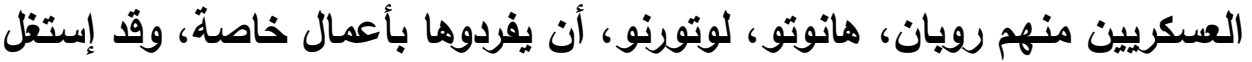

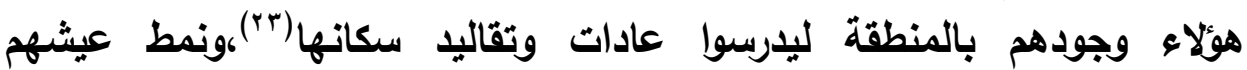

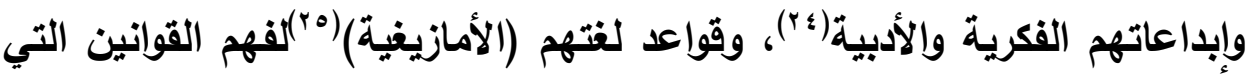
تسيير حياتهم الإجتماعية، بغرض السيطرة عليهم لا أكثر ولا أقله

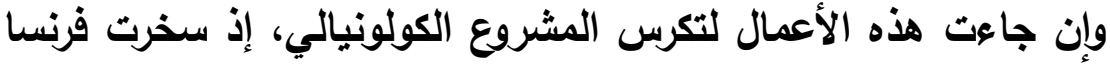

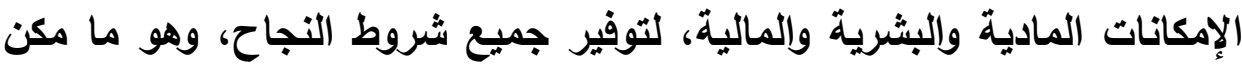
هانوتو في ظرف قياسي أن يمد الإدارة بعدد من الأعمال، التي وإن خدمتها في

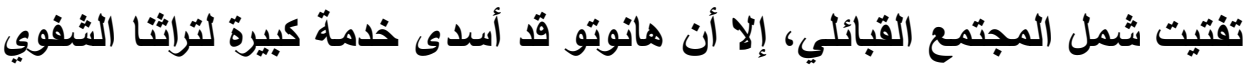

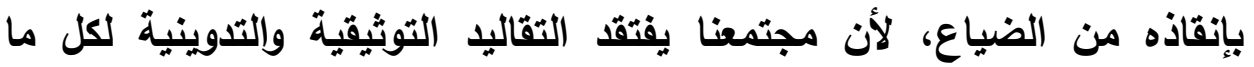
يخصه من قريب أويعيد. كما كان إميل مسكراي من الثخصيات الأكاديمية التي إهتمت بلدراسة

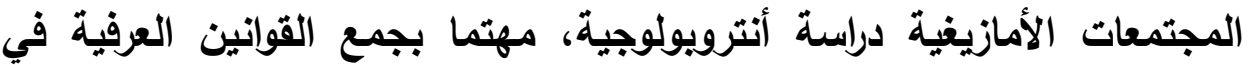

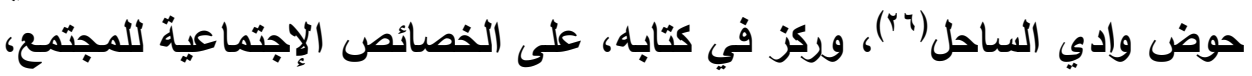

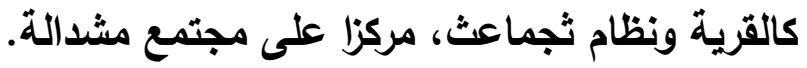
التهربف بـمنطقة مشندالة: إن من خصوصيات مشدالة -بلاية مايو - أنها واقعة على حدود مقاطعتين مهمتين وهما مقاطعة الوسط؛ الجزائر ومقاطعة الثرق؛ قسنطينة، فهي التي تقود 
حوض وادي الساحل الذي يصب في البحر المتوسط (بجاية)، وهي التي تفصل

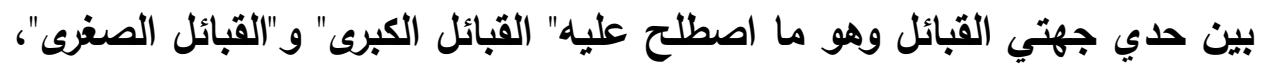

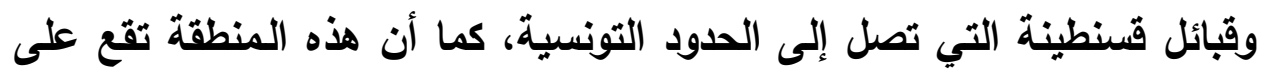

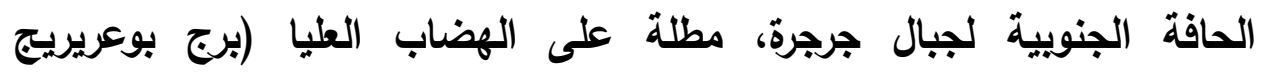

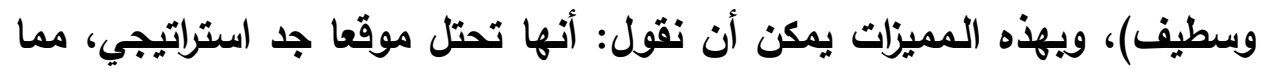

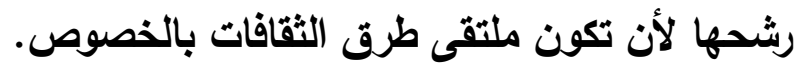

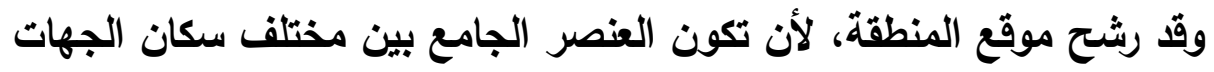

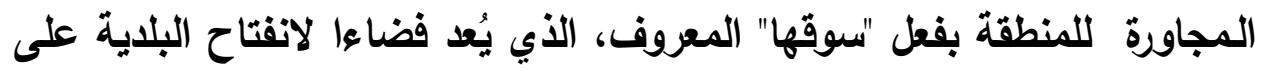

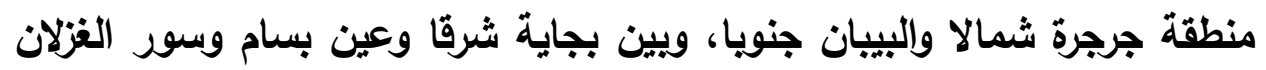

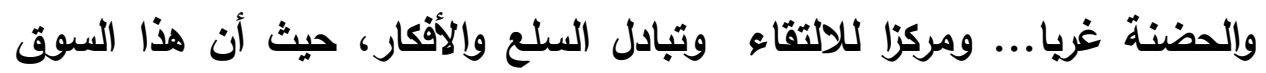

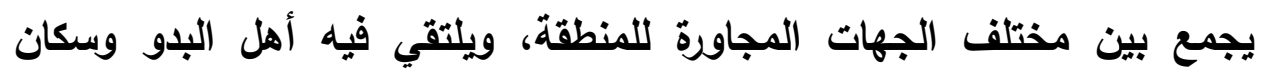

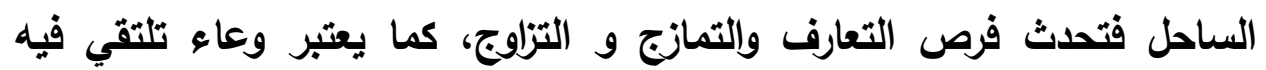

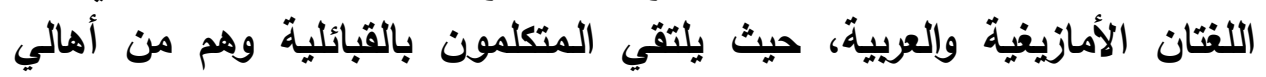

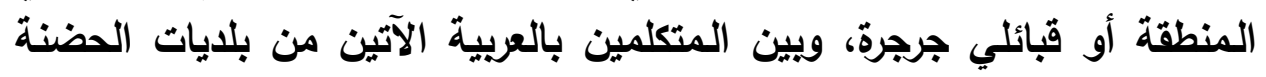

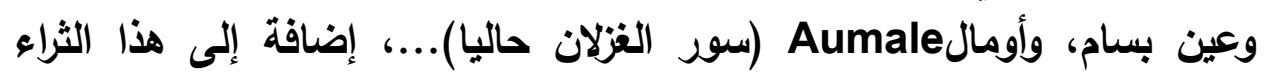

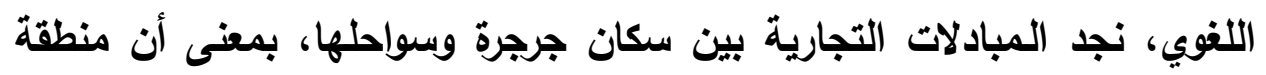

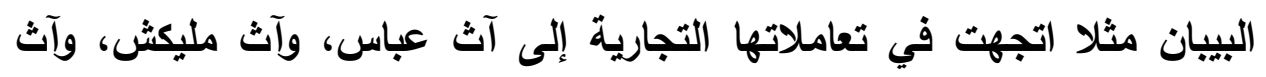

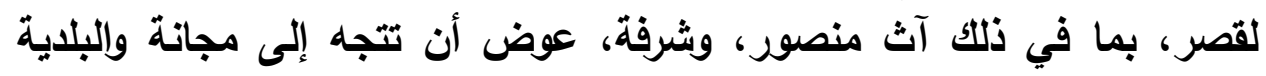
المختلطة للبيبان.

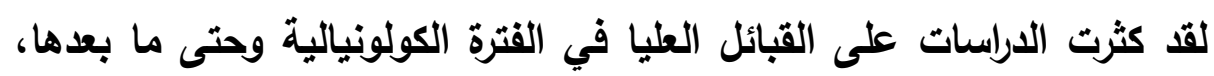

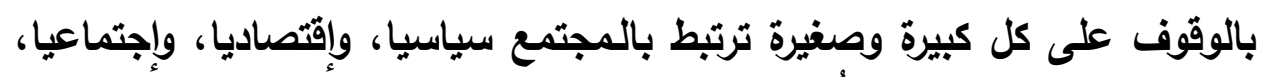

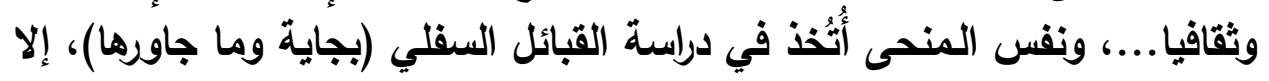

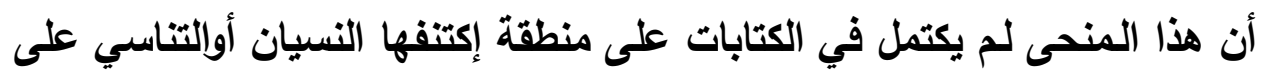

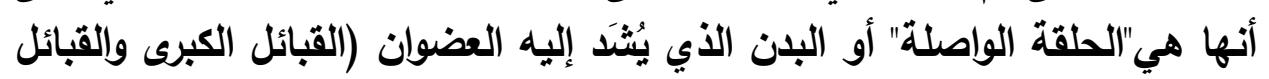

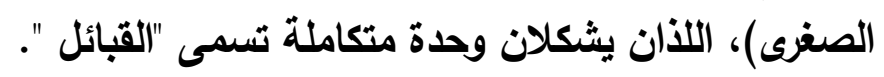

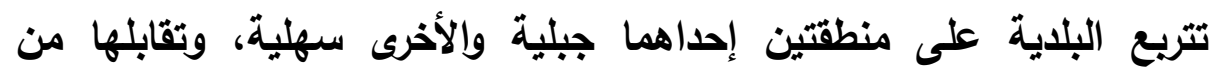

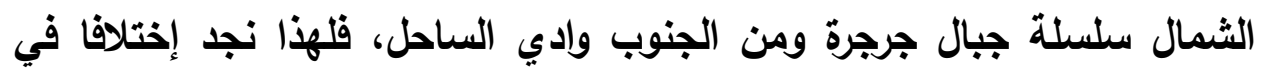
طبيعة تضاريس العروش المجاورة لها، والثواقعة بالجهة الثمالية، إذ تتخللها جبال 
اواقوران (واقور)، وآث كاني، وثيكسيغان، ويعض قرى امشدالن، أما المناطق

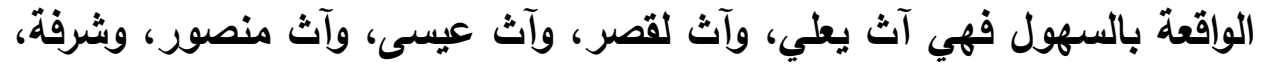
وسبخة، وقرى أخرى لمشدالة وهو ما ستثمله دراستنا.

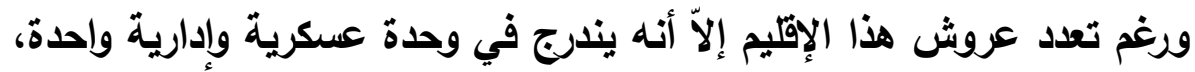

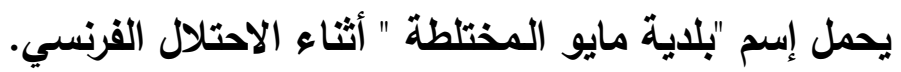

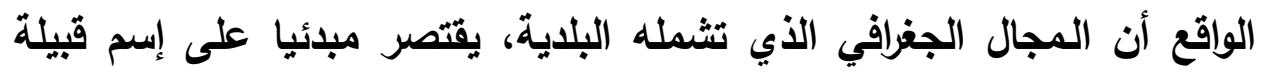

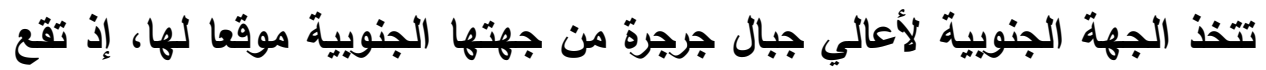

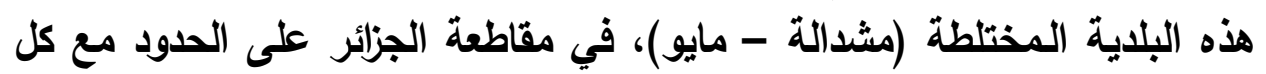

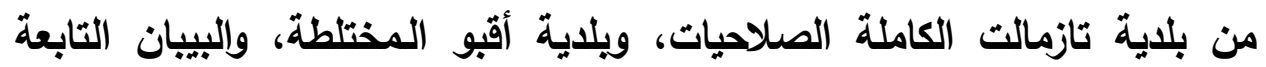

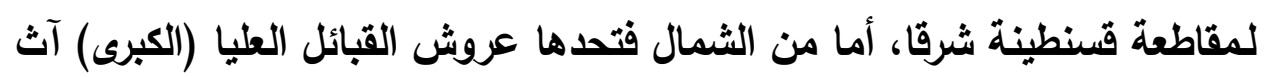
بوذلار، وآث بوعكاش التابعة للبلايتين المختلطتين جرجرة (عين الحمام حالياتيا)،

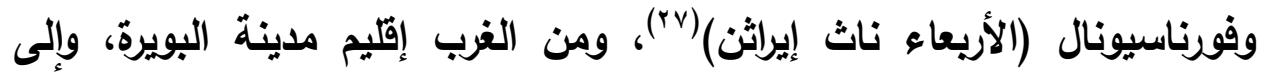

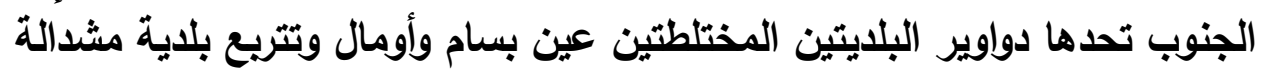

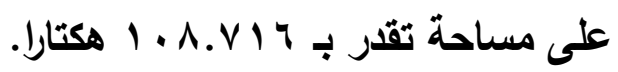

$$
\begin{aligned}
& \text { - أصل النسمية: }
\end{aligned}
$$

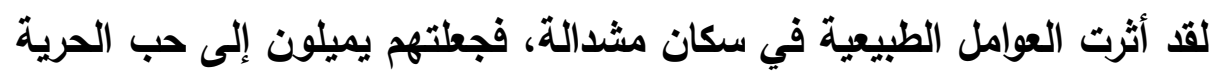

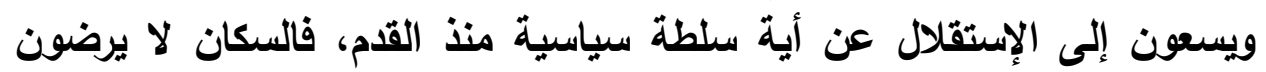

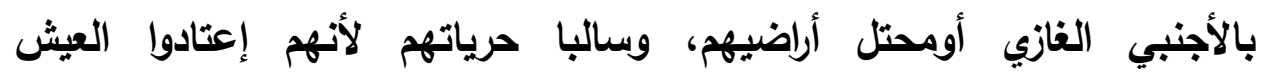

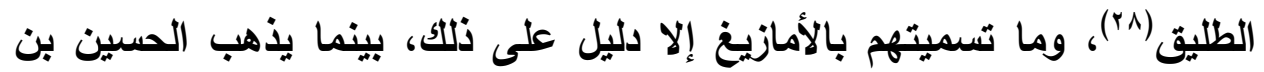

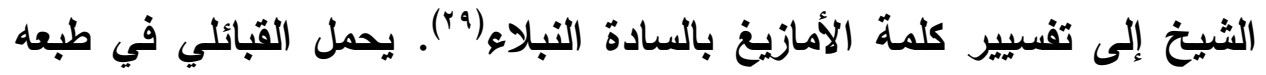

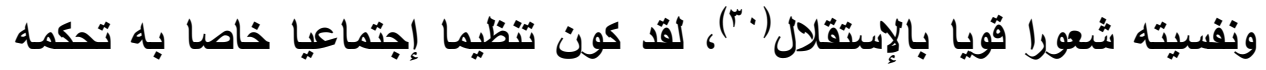
القوانين والأعراف المنبثقة عنه.

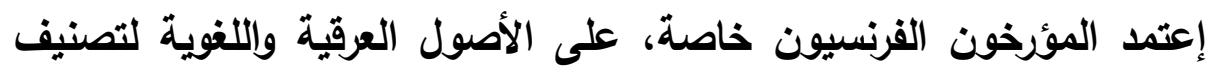

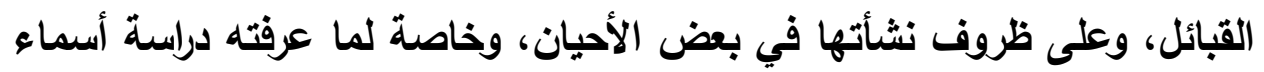

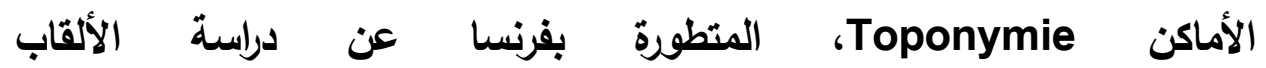

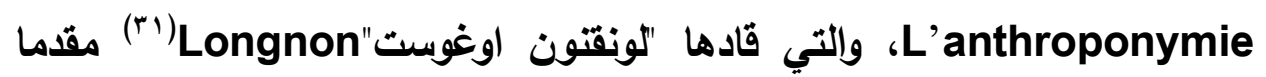
خدمات كبيرة لفهم سيرورة تاريخها، وهذا ما ينقص دراستتا لتفسير بعض الأسماء 
المتواجدة بالمنطقة، فبالنسبة لإسم قبيلة مثدالة، لم نكد نعثر على وثيقة تبين أصل التسمية، إلا ما تعلق بأصولها وجنة لإسترافيتها.

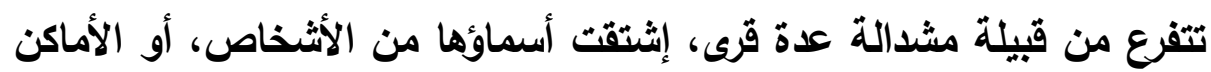

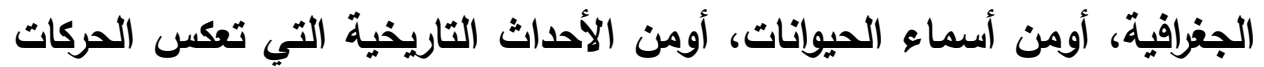

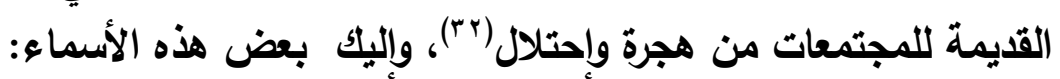
- أسماء ذات دلالة جغرافية:

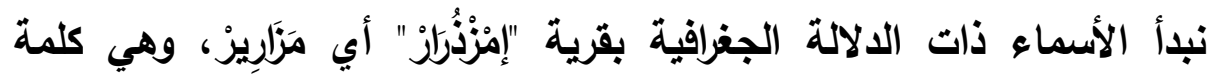

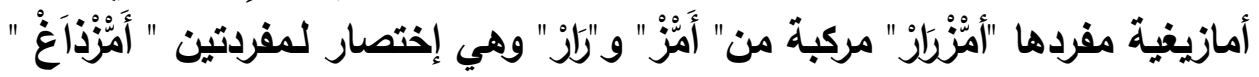

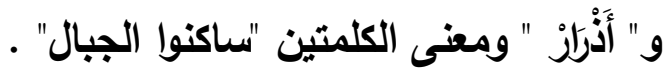

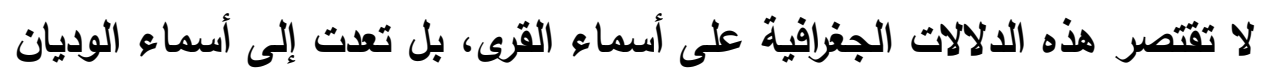

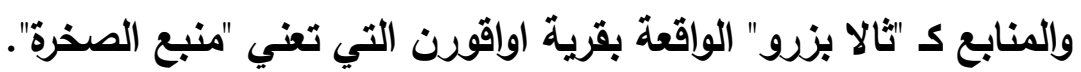

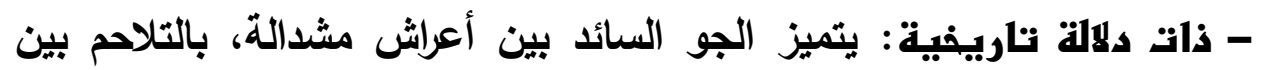

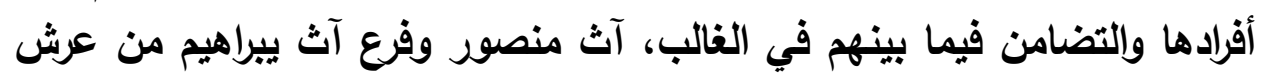

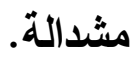

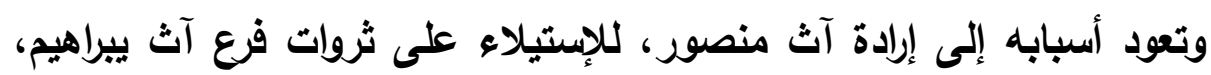

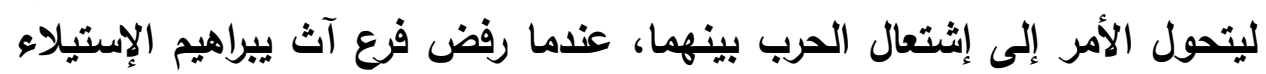

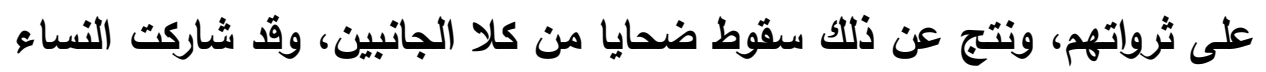

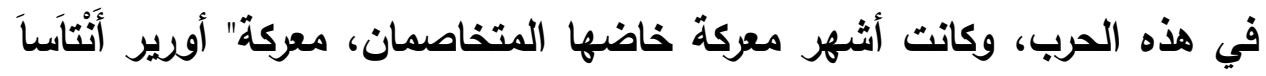

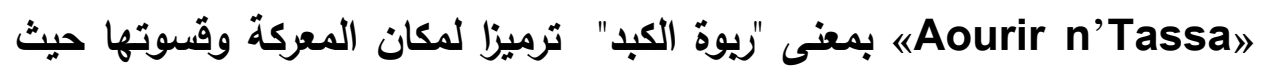
قامت خلالها إمرأة بنزع كبد أحد الخصوم. - مشنتقة من أسماء الأشخاص:

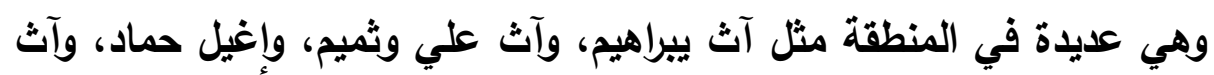

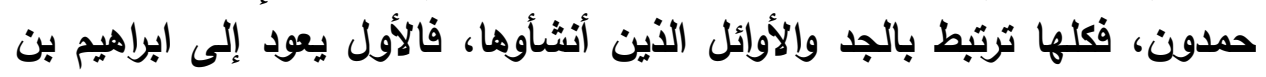

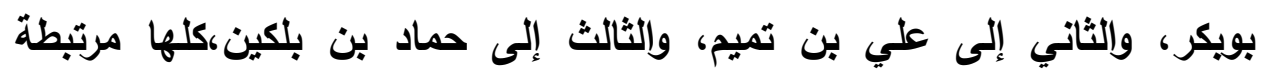

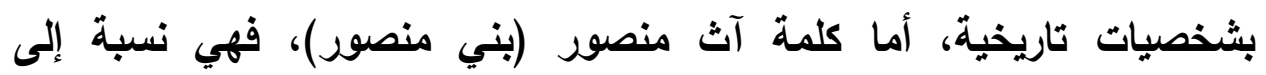

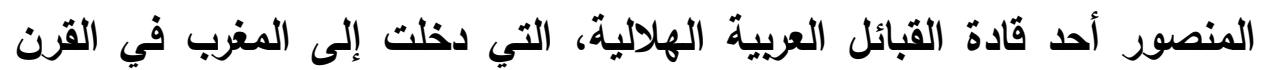

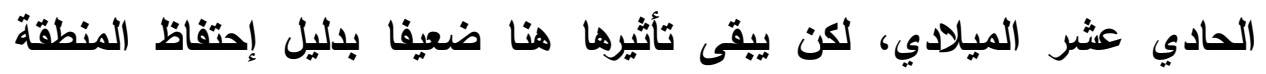
بجذورها البريرية ولغتها الأمازيغية. 


\section{- مشنتقة من أسماء الميوانات:}

كما نجد أسماء مناطق ذات دلالات حيوانية كثيكسيفذان، التي تجمع بين

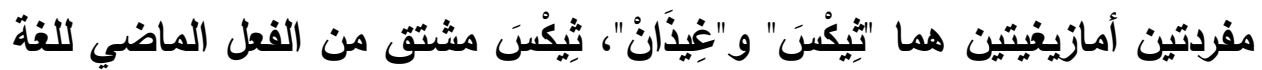

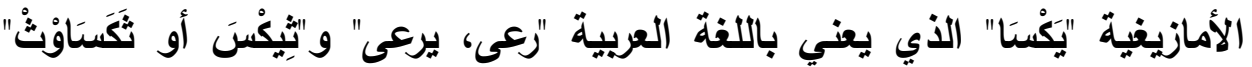

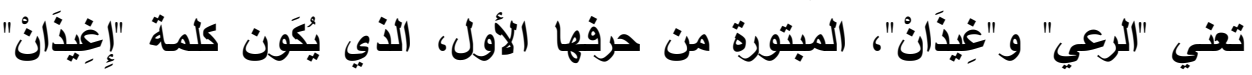

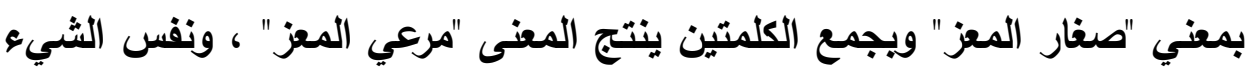
بالنسبة لقرية " إغيل أويازيظ " التي تجمع بدورها كلمتين "إغيل"ومعناه "الريوة "

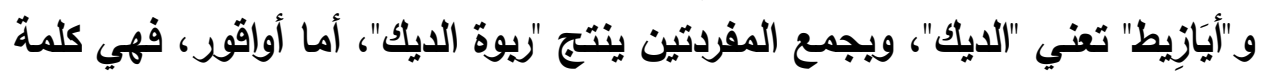
أمازيغية تعني إسما لنوع من الطيور. لا يمكن حصر الأسماء في هذه الدراسة، لذا فإنانا نتركها للمهتمين بأصول

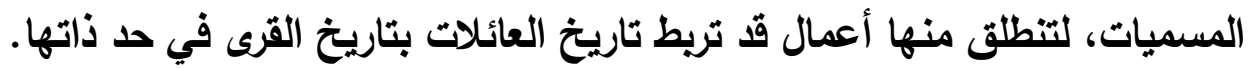

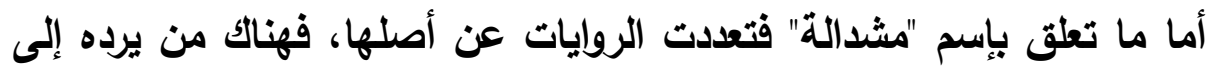

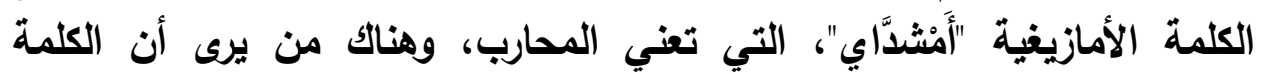

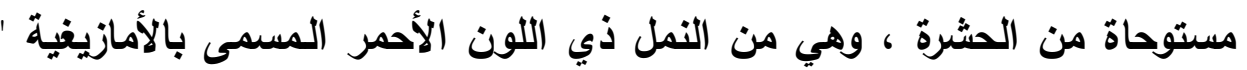

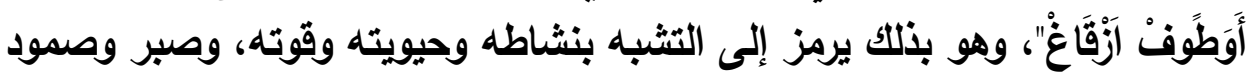
هذا المجتمع الأي يعمل ويجد كالنمل، بينما يمكن ترجيح الرأي الثالث الأي يقول

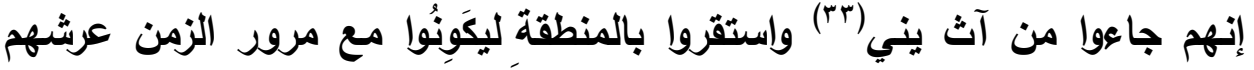
وقبيلتهم الخاصة، وهي الرواية التي وجدناها في الوثائق الأرشيفية (وثيقة Notabilité أن ينتقل مقرها إلى مايو مركز، وهذه الرواية تعود إلى السكان الأوائل للقبيلة،

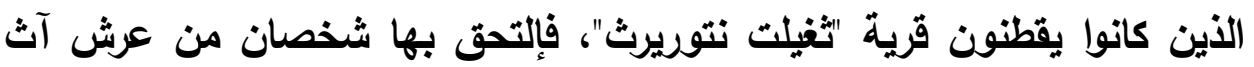

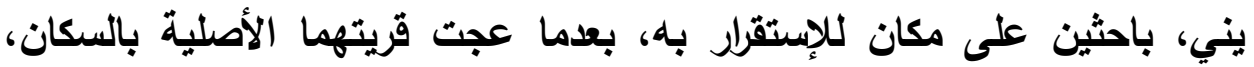

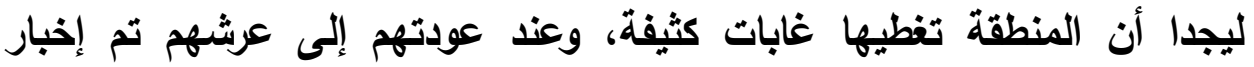

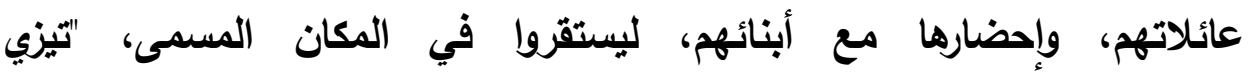

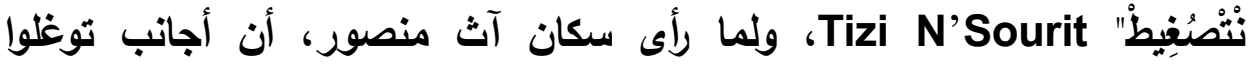

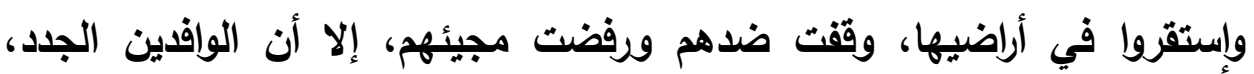
حافظوا على توازنهم أمام حملات المنصوريين، لينضموا إلى نظامهم العرفي، ولكن وفن فئن

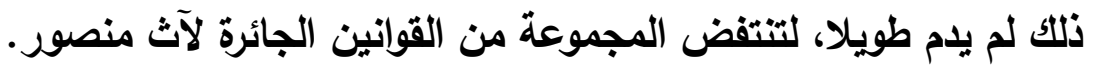


وقد تم الخروج من هذه الظروف الصعبة التي كان يعيشها وافدو آث يني، التي إني

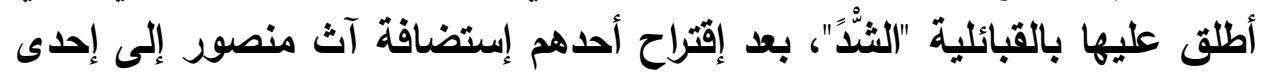
وولائمهم.

ويجب أن يتزامن طلب مسؤول الفرقة إحضار المأكولات للضيوف، مع تدخل

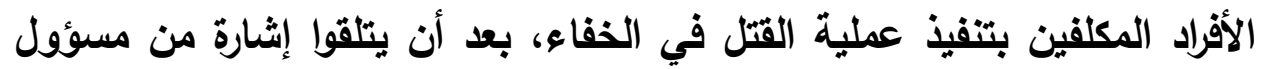

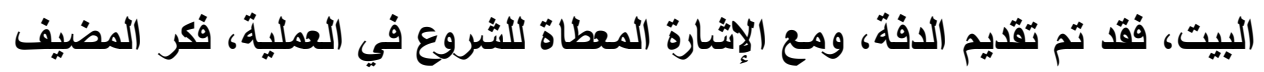

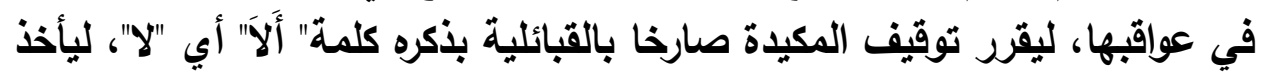

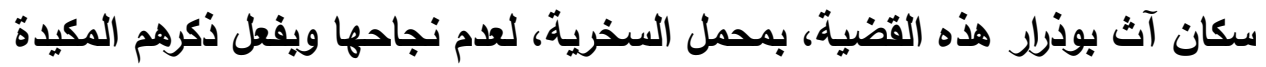

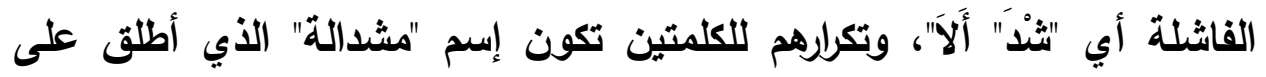

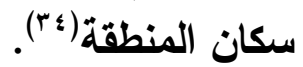

ومهما تعددت الروايات فإن العرش يعود إلى أصل بريري، وهو أحد بطون قبيلة

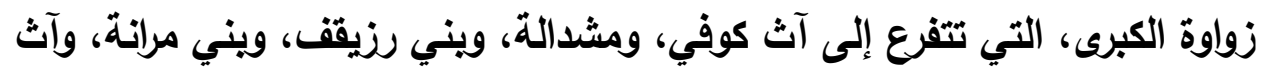

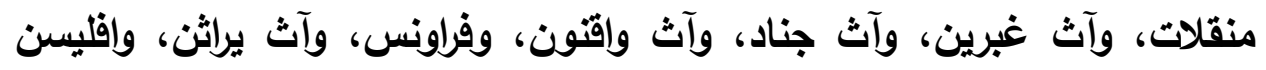
( ${ }^{(* 0)} \ldots$

ويعتبر عرش مشدالة الأهم بين العروش الأخرى، إذ تصل حدوده إلى قسم هام

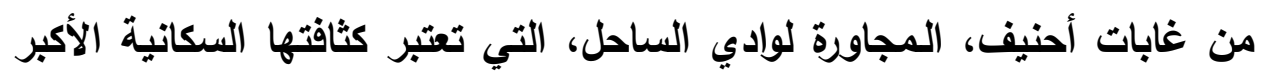

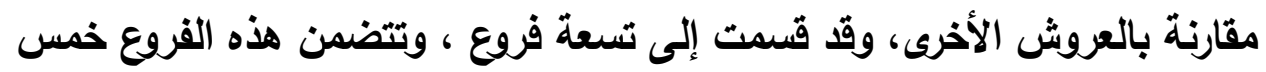
عشرة قرية. وتعود أهميتها إلى ماضيها التاريخي، فقد أثشار إليها ابن خلدون في كتابه العبر، على أنها بطن من بطون زواوة، القبيلة التي تنتمي إلى كتامة ذات التهائه الأصول

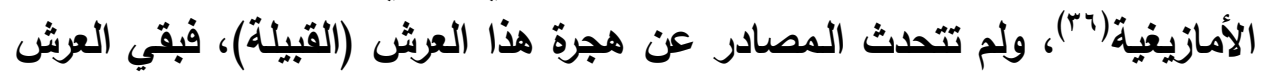

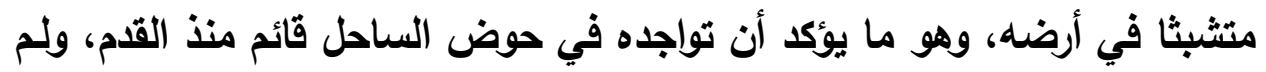

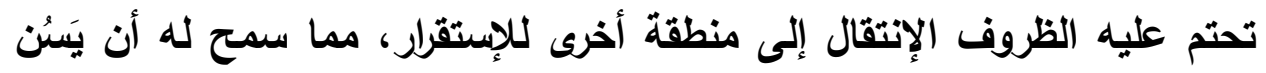

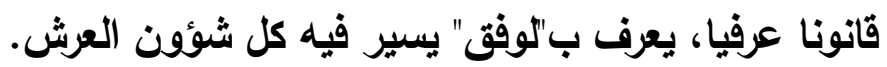

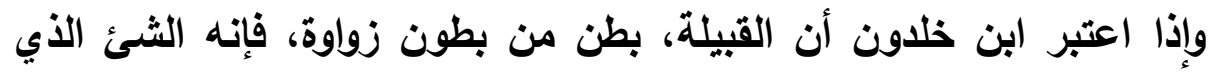
ذهب إليه أيضا (يرنست ميرسيي (M. Ernest Mercier

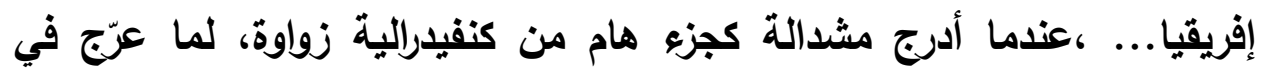
حليثه على منطقة زواوة في الفترة الإسلامية، كما خضعت مشداملة كألة لأمراء بجاية، 
ثم الأتراك، حيث إختارت إحدى قوافل باي قسنطينة، المكان المسمى"|إفثيسن"،

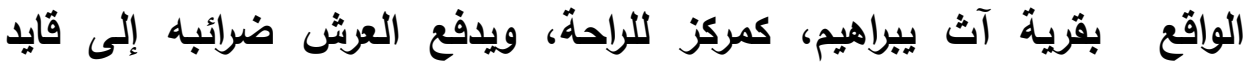

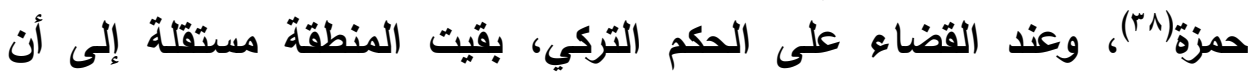

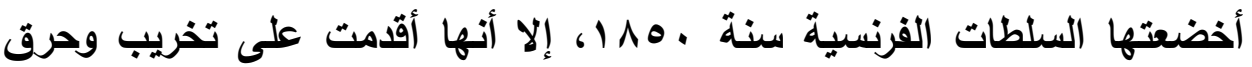

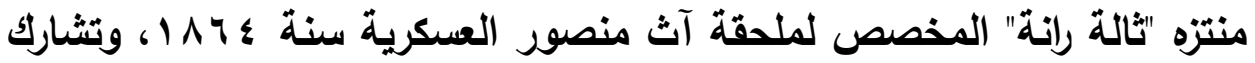

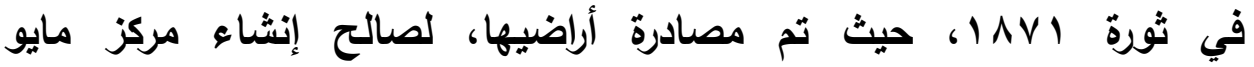

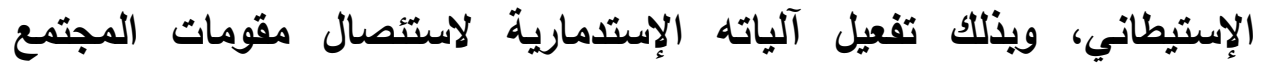
الجزائري الدينية والثقافية، وإفراغه مع تفكيك وحدته الكائة الإنتانة في نظامه القباني

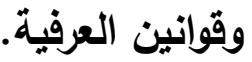

\section{المرأة والقوانين العرفية المشدالية:}

تعتبر القوانين العرفية ميزة هامة في بلاد القبائل، التي تترجم طبيعة

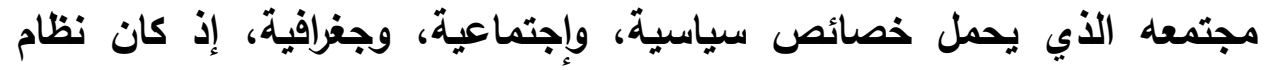

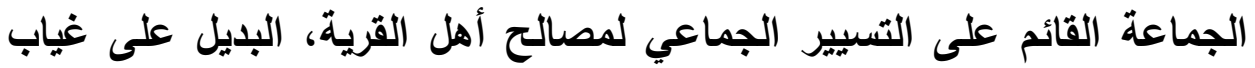

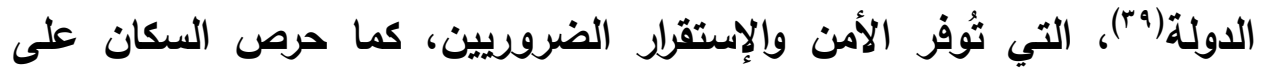

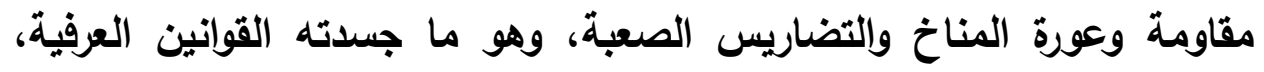

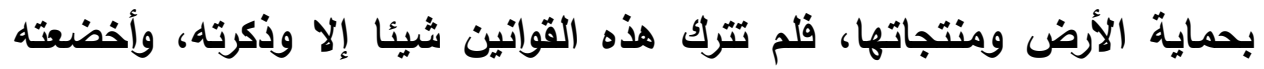

$$
\text { لقانون يحتمي به أهالي القرى. }
$$

يتضمن القانون أحكاما ردعية في مختلف الميادين، الثيء الذئي من فئن

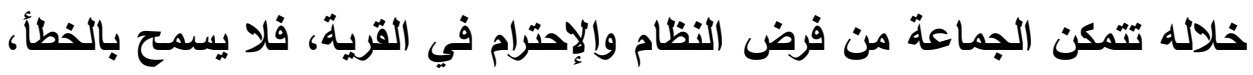

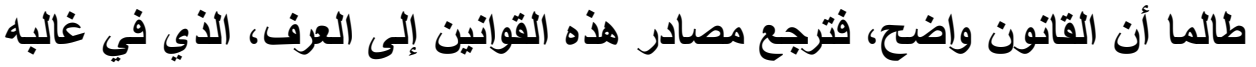

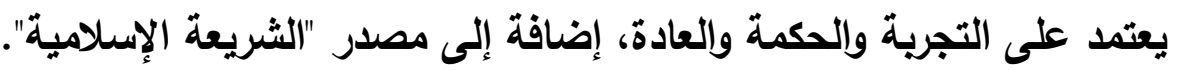

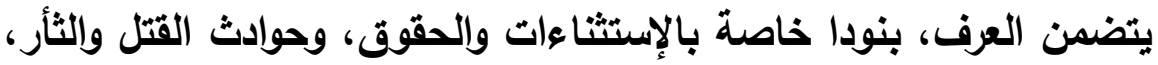

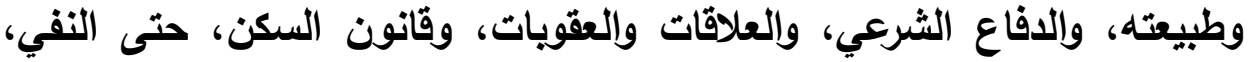

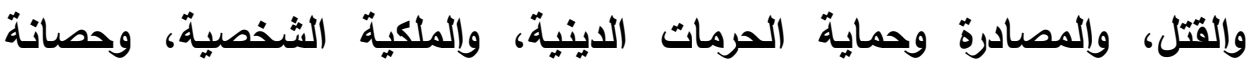

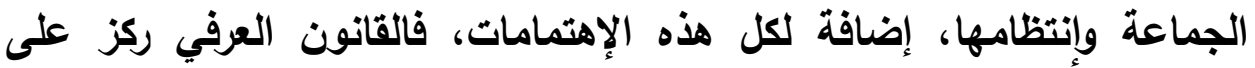

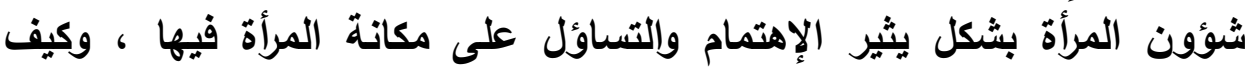

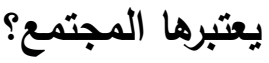


وللإجابة عن هذا التساؤل، لا بـ علينا من قراءة متأنية، نبرز من خلالها

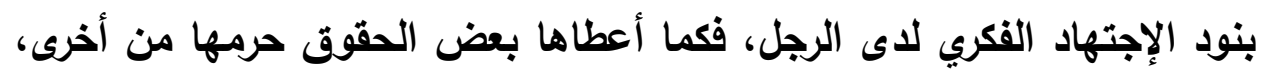
وهو ما سنبرزه هل هو في حماية المرأة، أوفي إذلاكها.

\begin{tabular}{|c|c|c|}
\hline الخاصة منها بالمر & مجموع المواد & القوانين (• ؛) \\
\hline$r V$ & 91 & عرش عدني \\
\hline 11 & $9 \leqslant$ & الجمعة نصهاريج \\
\hline 11 & 19 & عرش آث يعلى \\
\hline 17 & 10 & عرش آث لقصر \\
\hline 10 & $9 \wedge$ & عرش إمشدالن \\
\hline
\end{tabular}

يظهر لنا هذا الجدول، حضور المرأة في قوانين القرى والعروش بمنطقة القبائل، رغم عددها الصغير مقارنة بمجموع مواد القوانين، مما يوحي لنا بالصبغة الأكورية، التي صبغت بها هذه القوانين، وذلك راجع لهيمنة الرجل على مجريات الأحداث، وتحكمه في شؤون الحياة، وشؤون المرأة، التي يعتبرها ضلا تابعا لله، لكن هل يمكن أن نتزل إلى داخل هذه القوانين لمعرفتها حق المعرفة، وهل هي الماني

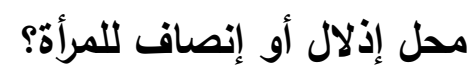
تمثل المرأة العمود الفقري للبيث، حتى أن الكثير من أهالي القبائل يرون في

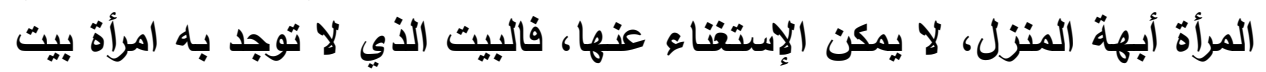

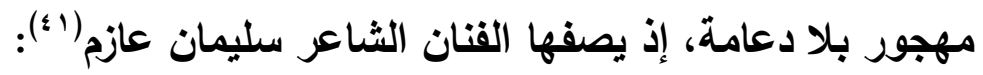

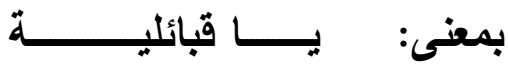

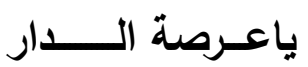

عليك بُني البيـت إعـاته
A Thaqbaylith

A Thigedjdith A Thin Fyebna Waxxam

ونظرا لتعدد إهتمامات سكان المنطقة، فإنهم لا يلتفتون كثيرا إلى حياة

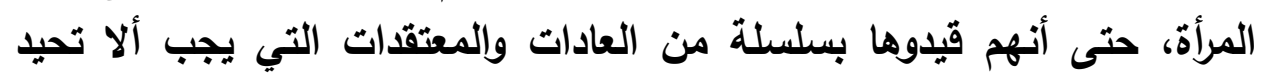

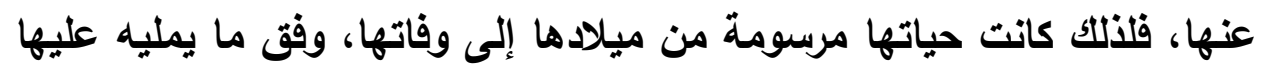

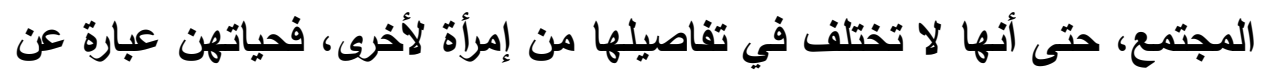
نسخة واحدة. 


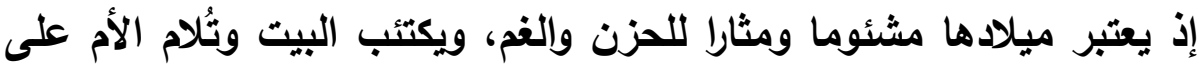

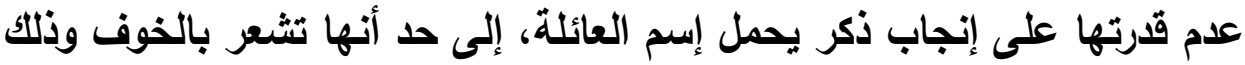

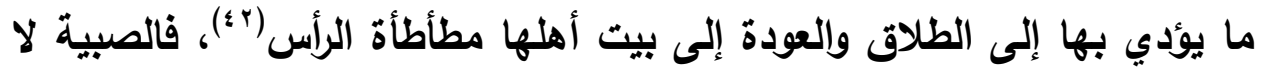
تلقى أدنى إهتمام، مقابل الإهتمام الأي يلقاه الصبي من جنس الأكور، فإذاذا

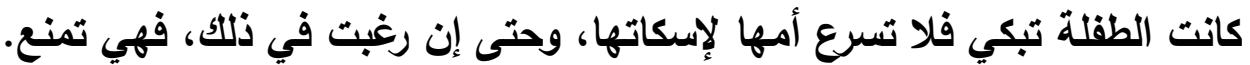

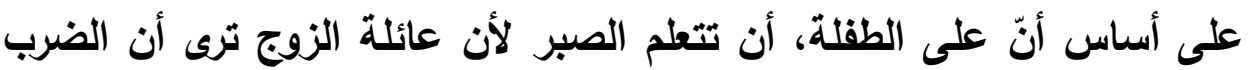

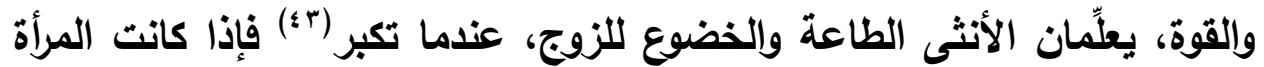
عاقرا فمصيرها الطلاق، أما إذا كانت منجبة للأكور، فهي ألكثر شأنا وقدرا في

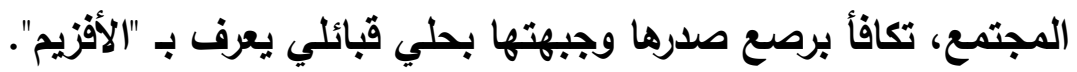

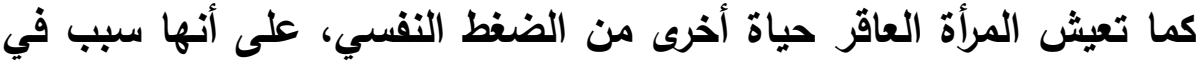
قلق العائلة، وزعزعة شرفها المهدد للبيت بأكمله، لذلك فهي عبه اهبه كبير وثُقيل عليه (؛)؛ يجب التخلص منه بتزويجها منذ الصغر، دون الأخذ برأيها، ويدون

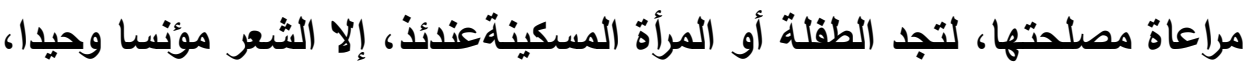

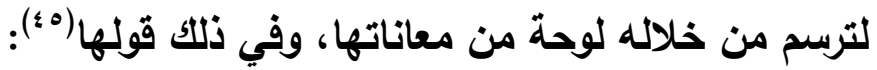
A yemma Henna Fkanniyi-Uraalim-agh

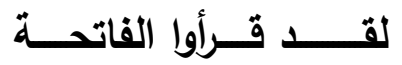
Ghran I'Fatiha

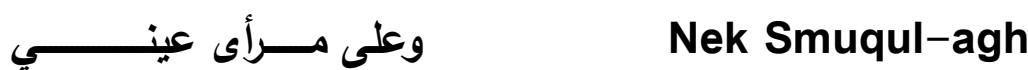

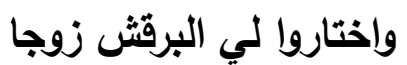
Da Bubar kach

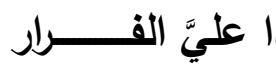
Azzeka ad Rewlegh هذا ويتم الزواج وفق مراسيم معينة وما تقتضيه تقاليا المجتمع، ويتكفل أهل

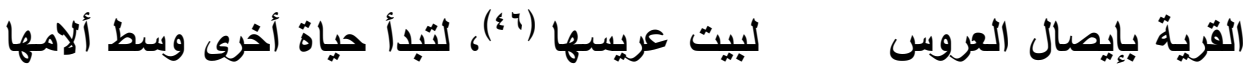
وأحزانها ومسؤولياتها، ويعاقب من تخلف عن ذلك، بغرامة قدرها ريالان

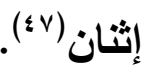

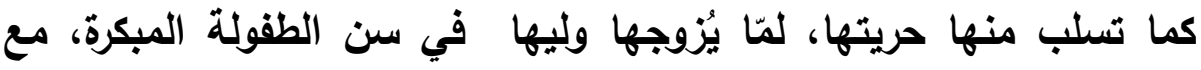

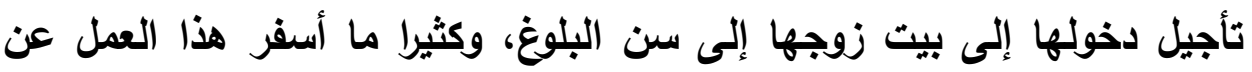

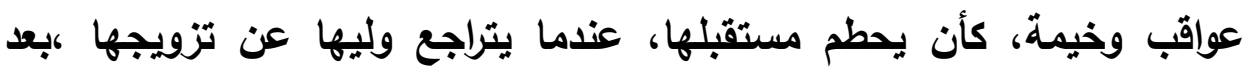
بلوغها سن الرشد، في حين يتمسك الرجل بها، بحجة أنها زوجته، فيقوم 
بتعليقها المعروف عند السكان ب" ثمحطنت أو ثمعوقث" أي برفض تطليقها،

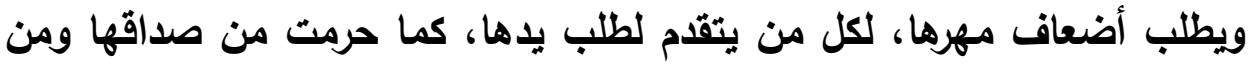

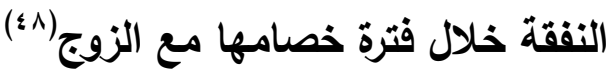

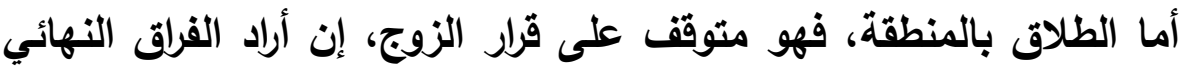

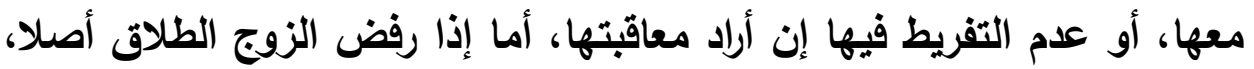

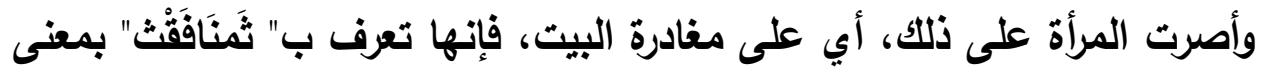

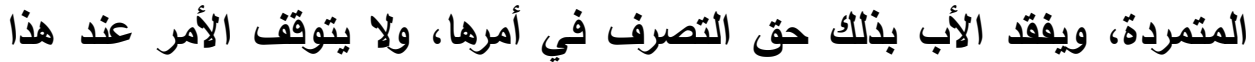

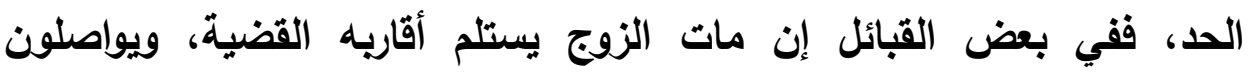
المطالبة بالمبلغ الذي حدده زوجها مقابل حريتها، كما منع زواج المرأة خلال

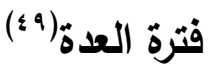

بالإضافة إلى كل هذا، فقد أنتزع منها حقها المشروع في الإسلام، وذلك وفي

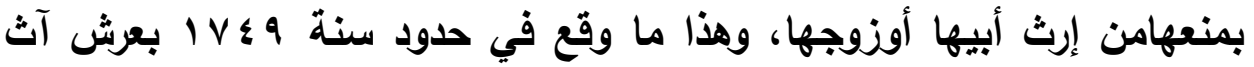

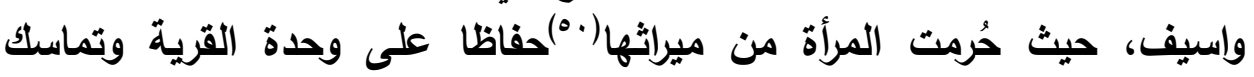

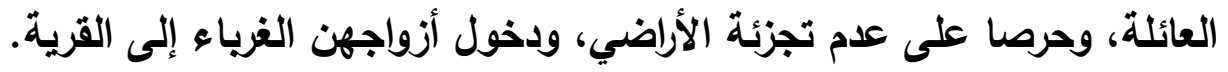

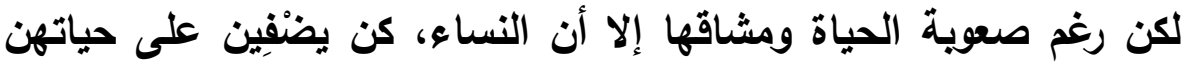

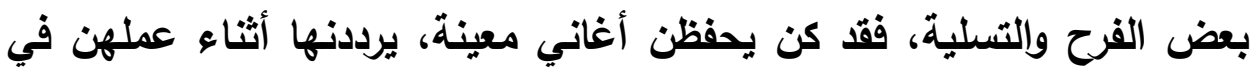
إدارة الطاحونة عند طدن القمح، أو خلال النسيج، أوعند قيامهن بإعداد الفئه الفخار

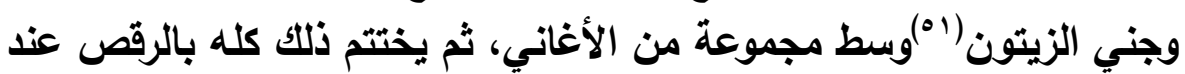

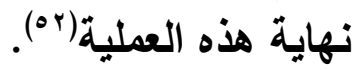
وترى القوانين العرفية أن حماية الأسرة، من حماية المرأة، وذلك بصون

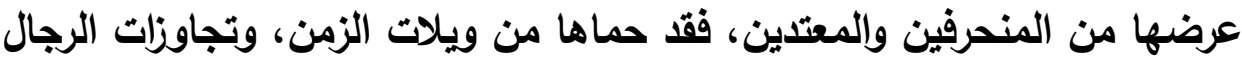

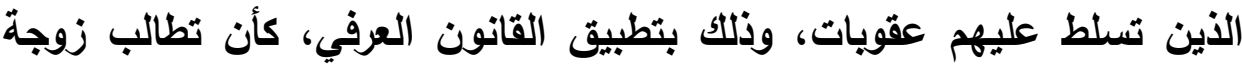

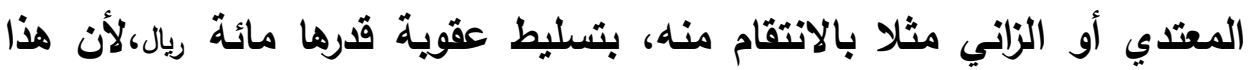

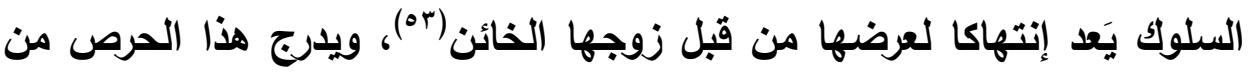

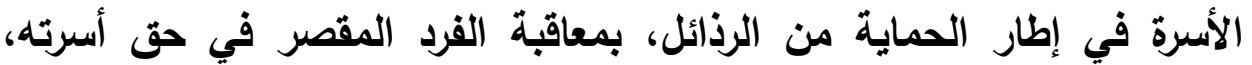
كإرتكابه الفواحش ، كما حارب قانون عرش آلآن آثان كاني، الفساد في الأعراض،

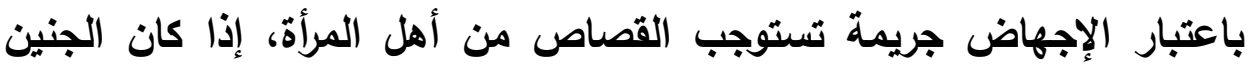

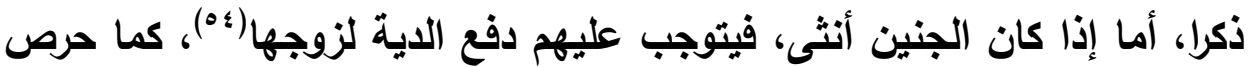


القانون العرفي على حماية الطفولة، عن طريق منح كفالة الرضيع للأم، في

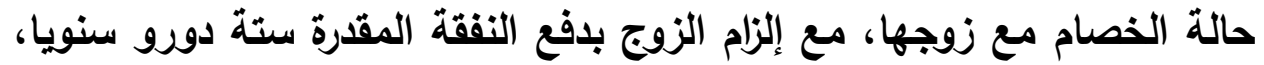

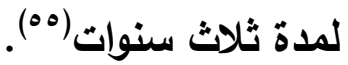
كما كفل القانون العرفي حقوق المرأة، بتخصيص قطعة أرض خصبة لهناء لهاء

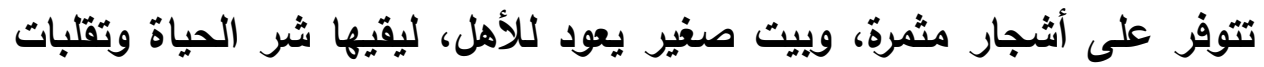

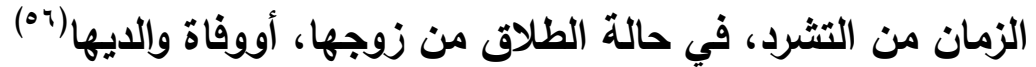

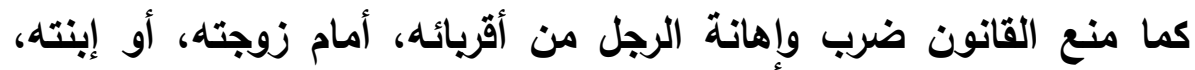

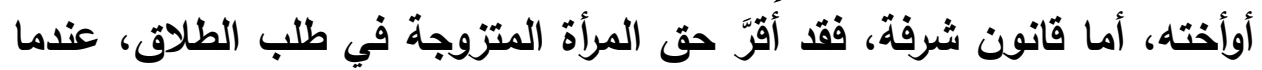

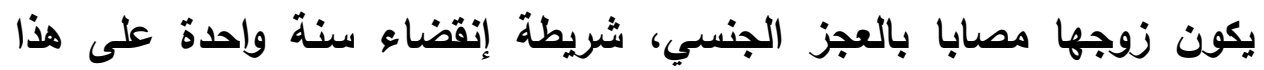

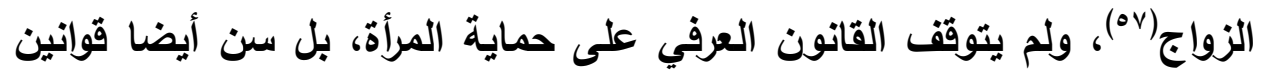

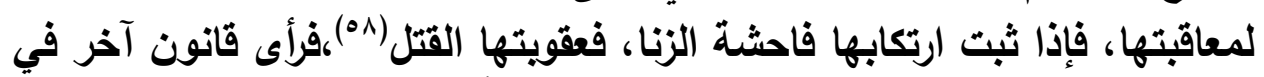

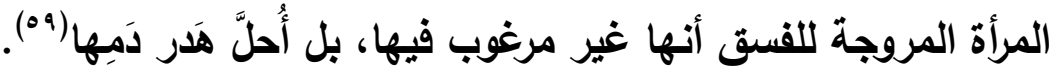

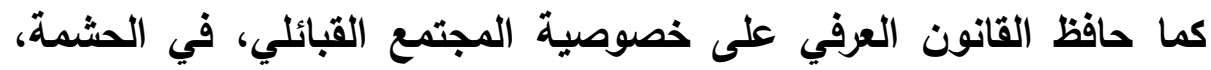

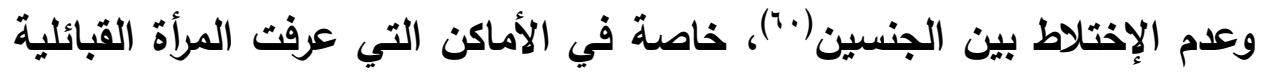

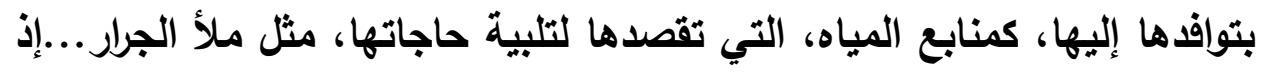

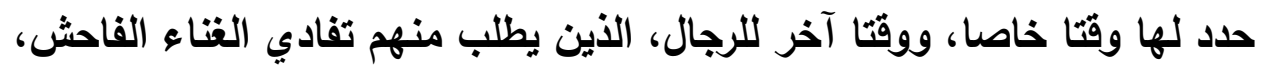

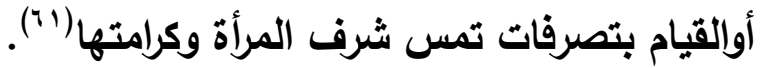

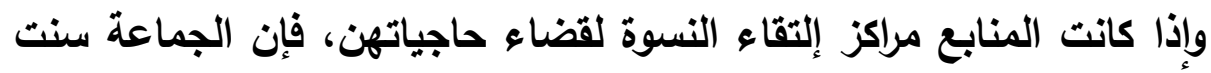

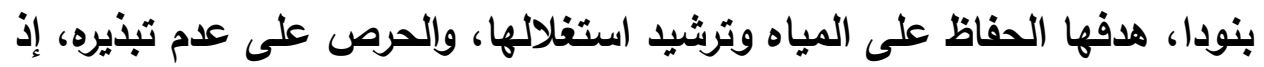
تعاقب كل امرأة تسرف في استغلال الماءو، أوإتخاذ المنبع كمغلة العاطة أو كمكان

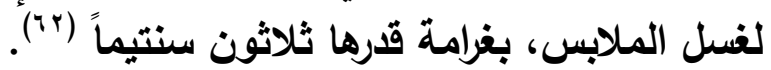

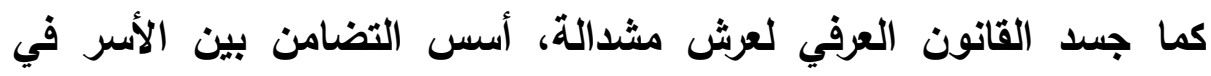

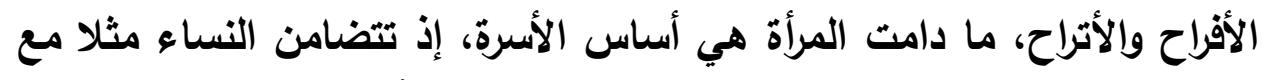

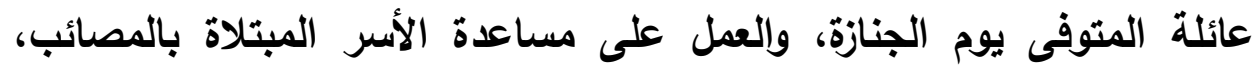

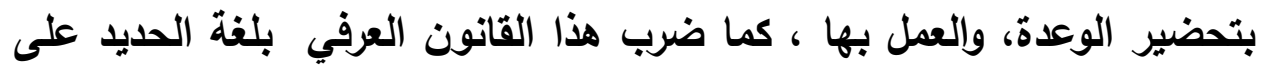

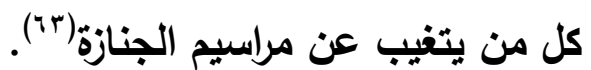
وما نستخلصه أن هذه القوانين إرتبطت بالظروف الإنتازئ الإنماعية الصعبة للمرأة، التي عاثتها في المجتمع القبائلي والبيئة الطبيعية القاسية، وجعلت منها كائنا 
في خدمة الرجل، تتحصر مهمتها في تربية الأبناءبالبيت، وما جسدته قوانين

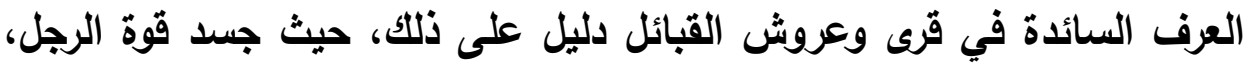

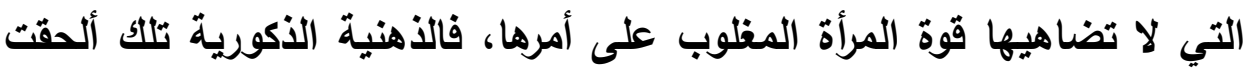

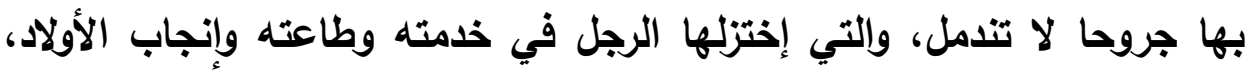
لكن رغم ذلك فإنه منحها بعضا من حقوقها، التي تحميها أحيانا من غرور

\section{مواشي البهث:}

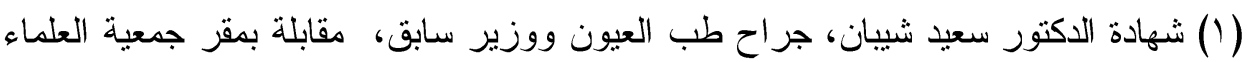

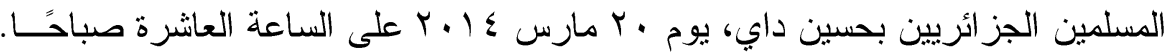

$$
\text { (r) }
$$

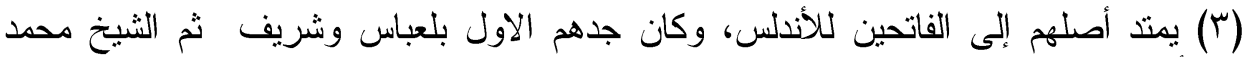

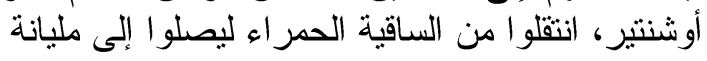

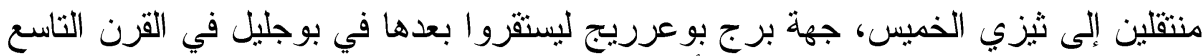

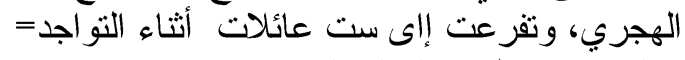

= الفرنسي بتطبيق الحالة المدنية منها هنية وبن سعد ل... و الثشيخ علي أوشنتير ينتمي لهذه العائلة. . - العرن

( $\left.{ }^{4}\right)$ Hanoteau et Letourneux, , La kabylie et les coutumes Kabyles, T1, $2^{\text {éme }}$ Édition, Challamet, Paris, 1893., p. 61.

( 5 ) Alain Mahé, Histoire de la Grande Kabylie XIXè-XXè Siècles, Anthropologie Historique du Lien Social dans les Communautés Villageoises, Editions Bouchene, 2000, (778), p. 106.

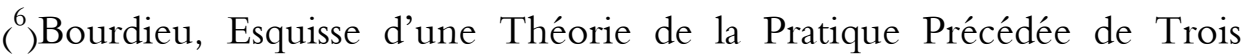

Etudes Ethnologie Kabyle, Paris et

Genève, Droz, 1977, ,pp. 15-44.

() Alain Mahé, op.cit., p. 106.

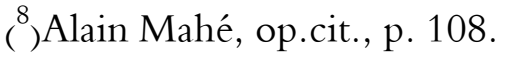

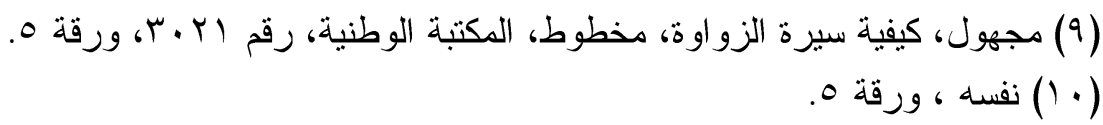

(10) Rozet et Carette E, Algérie, Paris, Firmin Didot Frères, Edition Imprimeuse de l'Institut, 1850, p. 220. 
(1) حمدان بن عثمان خوجة، المرأة، تقديم وتعريف وتحقيق محمد العربي الزبيرب،

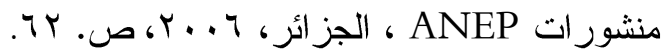

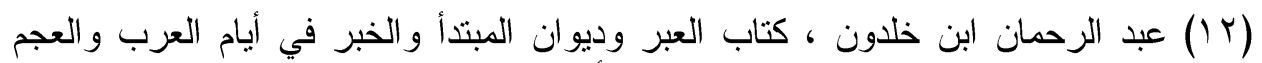

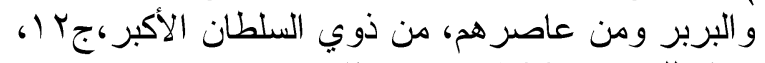

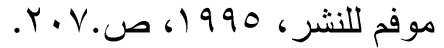

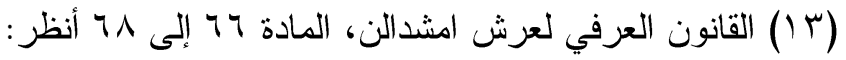

- Hanoteau et (A) Letourneux, la Kabylie et les Coutumes Kabyles, T III, Edition Bouchene, Paris, 2003, p. 303.

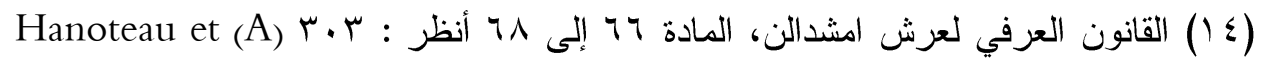
Letourneux, op.cit., p.

(15) Daumas ( $M$ ) et Faber ( $M$ ), La Grande Kabyle étude historique, Libraires de l'Université Royale de France, 1847, p.38.

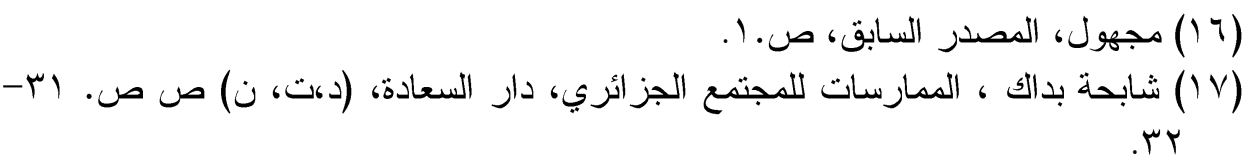

(18) Hanotaux et Letourneux (A), op. cit., T1, Imprimerie Nationale MD GGGL XX II, Paris, p.345.

(19) Idem, p.345.

(r. ) هي قيونة، منطقة واقعة في شمال البرازيل بقارة أمريكا اللاتينية، إتخدتها السلطات

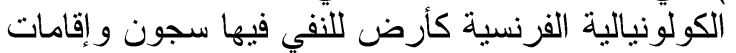

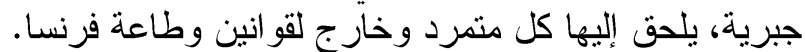

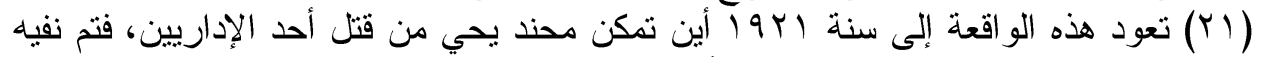

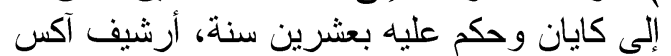

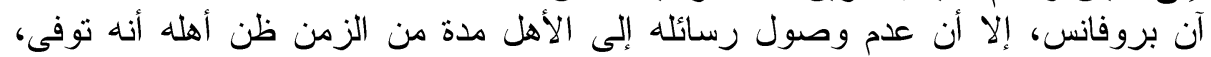

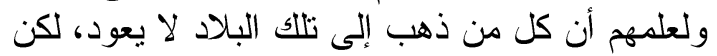

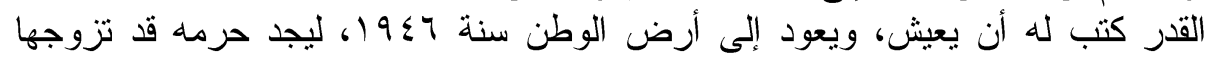

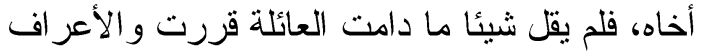

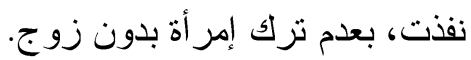

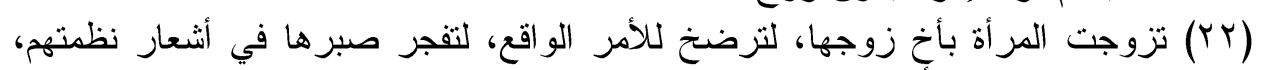

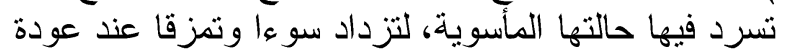

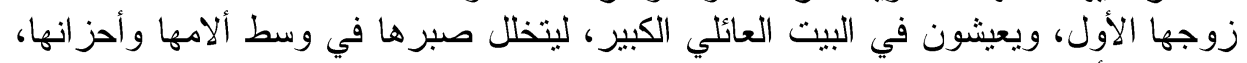

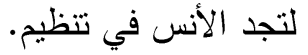


La Kabylié et les أصدر هانوتو كتابه المعنون: منطقة القبائل وطبائع أهلها (Y) هائوت في مفنة Cotumes Kabyles هانوتو في مقدمة كتابه، على أهية هذا الإنجاز العلمي في مساعدة الإنيرة الإدارة القرنسية، على بسط نفوذها على المنطقة.

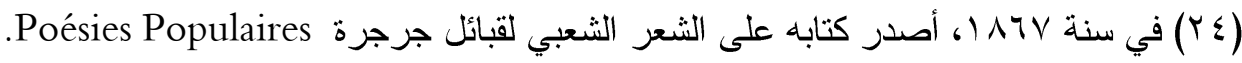
de la Kabulié de Djurdjura

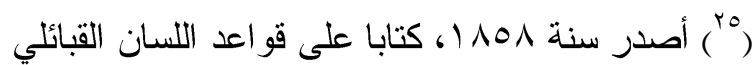

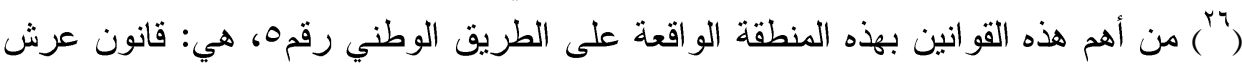

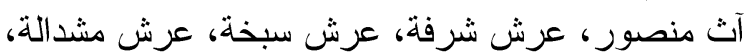
عرش، عرش آث يعلى، ورش شُش آث كاني، وعرش عرش آث عيسي، وعرش آث لقصر أنظر: .- Emiles Masqueray, Formation des Cités chez les Populations Sédentaires de l'Algérie (Kabylie du djurdjura,

Chaouia de L'Aurés et Beni Mzab), Ed. Sud, Lacalade, Aix-enProvence, 1883 , pp263-318.

( ${ }^{27}$ ) C.A.N. (national chivesrA'Centre d), Fonds Microfilm, Bobine $1 \mathrm{HH}$ 14, Statistique des Ordres Religieux- Récapitulation Cercle, Commune Mixte, Commune pleine Exercice, division d'Alger Année 1851.

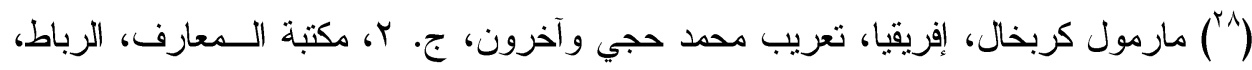
(I)

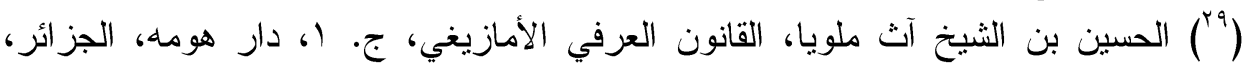

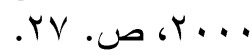

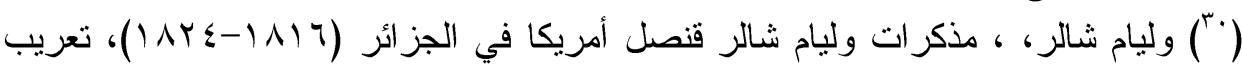

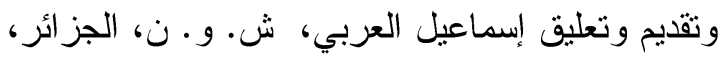

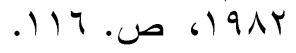

${ }^{31}$ ) Albert Dauzat, les Noms de Lieux, origines et évolution, villes et villages, Pays-Cours d'eau, Montagneslieux dits, Librairie Delagrave, Paris, 1932, p. 1.

$\left({ }^{32}\right)$ Idem.

${ }^{33}$ ) A .privée chivesrA) P), Notabilités 1892. 
مجلة كلية الآداب، جامعة سوهاج، العدد الثاني والخمسون، الجزء الأول، يوليو 19 • بم

$\left.{ }^{34}\right)$ Manuel Bugeja, «Monographie de la Commune Mixte de Bni Mansour (Département D’Alger) », bulletin

de la Société de Géographie d'Alger et de l'Afrique du Nord, Tome Vingt Six, Année 1921, pp. 58-59.

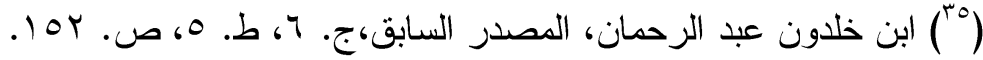

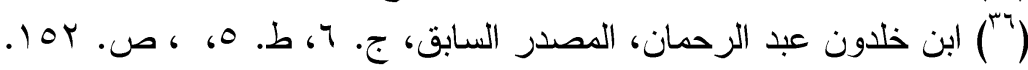

( ${ }^{37}$ ) M. Ernest Mercier, Histoire de l'Afrique Septentrionale(Berbèrie)

Depuis les Temps les Plus Reculés Jusqu'

à la Conquête Française, T.1, Ernest Leroux Editer, Paris, 1888, p .59.

( $\left.{ }^{38}\right)$ Manuel Bugeja, op.cit., p.59.

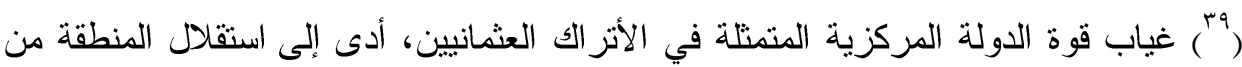

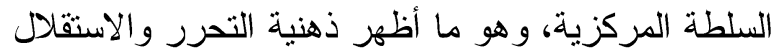

(40) Hanoteau et Letourneux, op.cit., pp. 300-310 .

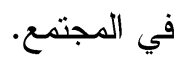

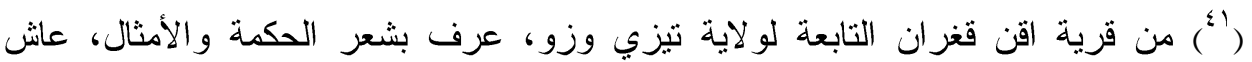

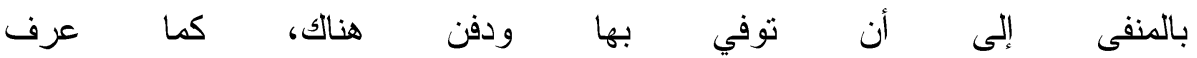

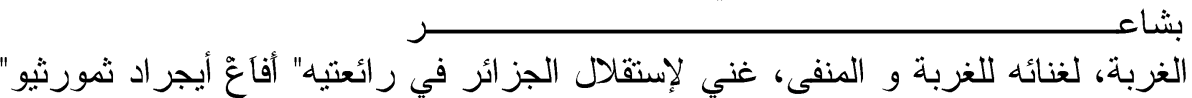

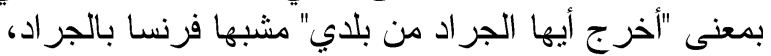

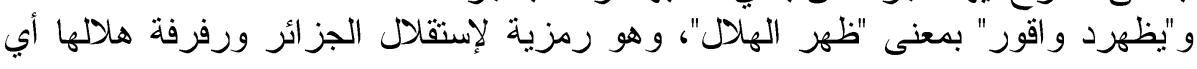
علمها.

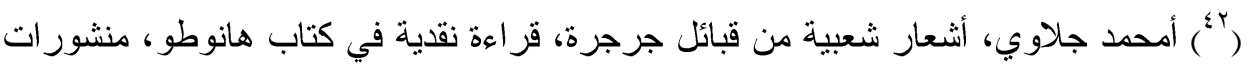

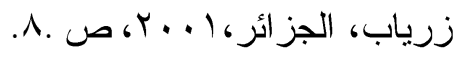

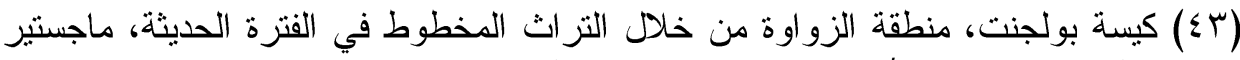

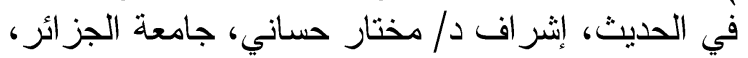

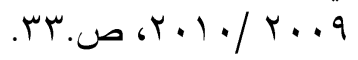

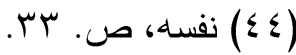

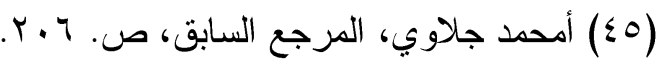

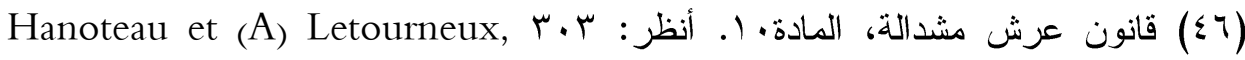
op.cit., p.

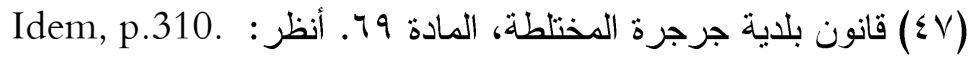

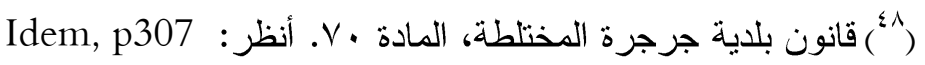




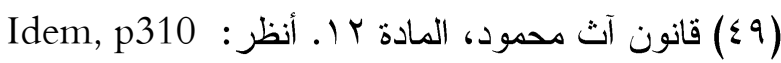

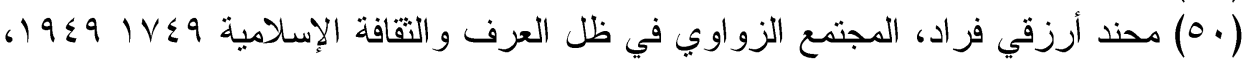

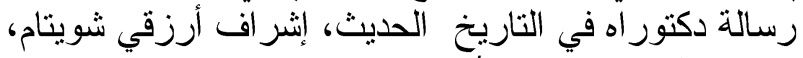

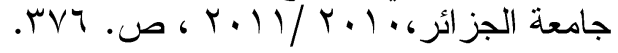

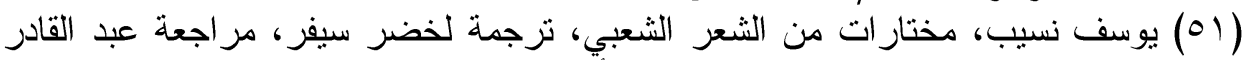

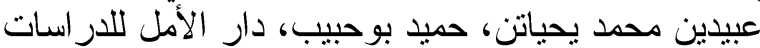

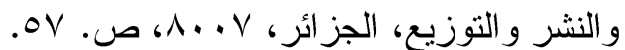

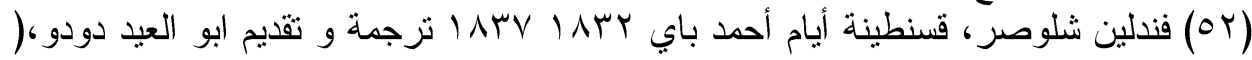

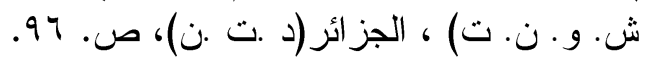

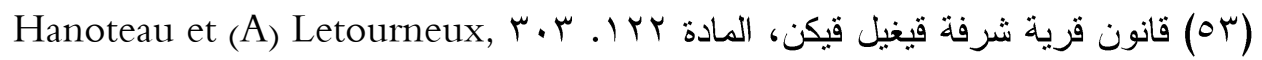
op.cit., p.

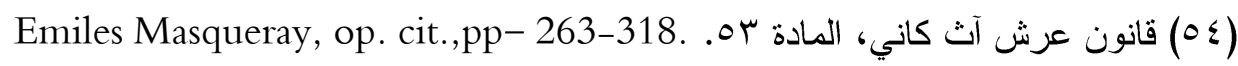

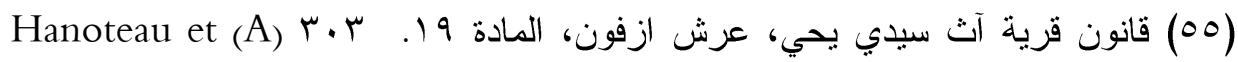
Letourneux, op.cit., p.

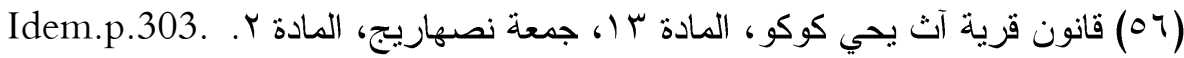

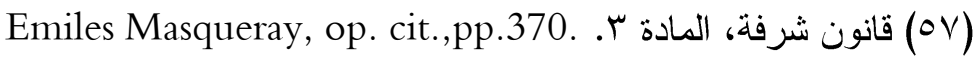

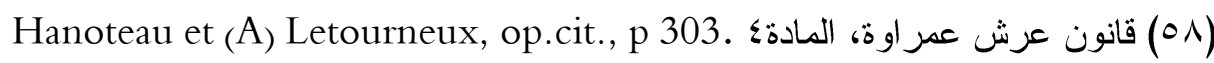

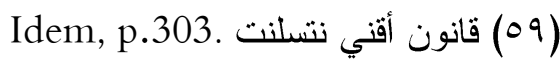

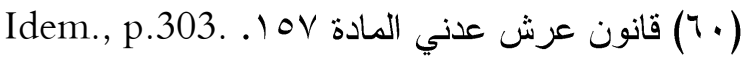

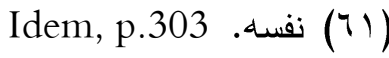

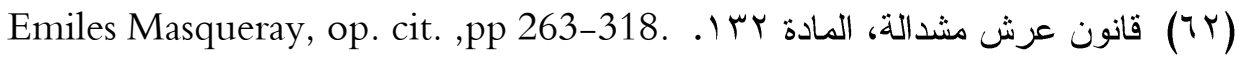

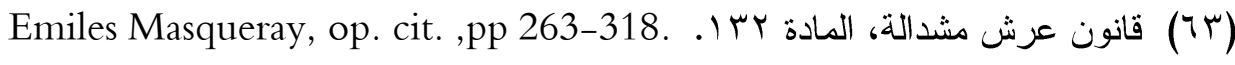

